\title{
Seismic Texture Applied to Well Calibration and Reservoir Property Prediction in the North Central Appalachian Basin
}

\author{
Connor Gieger
}

Follow this and additional works at: https://researchrepository.wvu.edu/etd

\section{Recommended Citation}

Gieger, Connor, "Seismic Texture Applied to Well Calibration and Reservoir Property Prediction in the North Central Appalachian Basin" (2017). Graduate Theses, Dissertations, and Problem Reports. 5674.

https://researchrepository.wvu.edu/etd/5674

This Thesis is protected by copyright and/or related rights. It has been brought to you by the The Research Repository @ WVU with permission from the rights-holder(s). You are free to use this Thesis in any way that is permitted by the copyright and related rights legislation that applies to your use. For other uses you must obtain permission from the rights-holder(s) directly, unless additional rights are indicated by a Creative Commons license in the record and/ or on the work itself. This Thesis has been accepted for inclusion in WVU Graduate Theses, Dissertations, and Problem Reports collection by an authorized administrator of The Research Repository @ WVU. For more information, please contact researchrepository@mail.wvu.edu. 


\title{
Seismic Texture Applied to Well Calibration and Reservoir Property Prediction in the North Central Appalachian Basin
}

\author{
Connor Gieger \\ Thesis submitted \\ to the Eberly College of Arts and Sciences \\ at West Virginia University \\ in partial fulfillment of the requirements for the degree of \\ Master of Science in \\ Geology
}

\section{Dengliang Gao, Ph.D., Chair \\ Thomas Wilson. Ph.D. \\ Timothy Carr, Ph.D}

Department of Geology and Geography

Morgantown, West Virginia

2016

Keywords: Seismic texture, calibration, Marcellus, 3D seismic, Appalachian basin Copyright 2017 Connor J. Gieger 


\section{ABSTRACT \\ Seismic Texture Applied to Well Calibration and Reservoir Property Prediction in the North Central Appalachian Basin}

\section{Connor J. Gieger}

Enhancing seismic interpretation capabilities often relies on the application of object oriented attributes to better understand subsurface geology. This research intends to extract and calibrate seismic texture attributes with well log data for better characterization of the Marcellus gas shale in north central Appalachian basin. Seismic texture refers to the lateral and vertical variations in reflection amplitude and waveform at a specific sample location in the 3-D seismic domain. Among various texture analysis algorithms, here seismic texture is characterized via an algorithm called waveform model regression utilizing model-derived waveforms for reservoir property calibration. Altering the calibrating waveforms facilitates the conversion of amplitude volumes to purpose-driven texture volumes to be calibrated with well logs for prediction of reservoir properties in untested regions throughout the reservoir.

Seismic data calibration is crucial due to the resolution and uncertainty in the interpretation of the data. Because texture is a more unique descriptor of seismic data than amplitude, it provides more statistically and geologically significant correlations to well data. Our new results show that seismic texture is a viable attribute not only for reservoir feature visualization and discrimination, but also for reservoir property calibration and prediction. Comparative analysis indicates that the new results help better define seismic signal properties that are important in predicting the heterogeneity of the unconventional reservoir in the basin. Provisions of this research include a case study applying seismic texture attributes and an assessment of the viability of the attributes to be calibrated with well data from the Marcellus Shale in the north central Appalachian basin. Examples from this study will provide insight in its capabilities in practical applications of seismic texture attributes in unconventional reservoirs in the Appalachian basin and other basins around the world. 


\section{ACKNOWLEDGMENTS}

I would like to thank Dr. Dengliang Gao for advising this research and providing seismic attribute datasets derived from his computer algorithms that made this research possible. I would also like to thank Dr. Tom Wilson and Dr. Tim Carr for serving on my committee and providing intellectual support and programmatic guidance for this project. Special thanks are owed to the Department of Geology and Geography at West Virginia University for providing the opportunity to complete this project and providing me a position as a teaching assistant position. I also would like to thank Energy Corporation of America and Cole Bowers for providing the data used in this research. 


\section{TABLE OF CONTENTS}

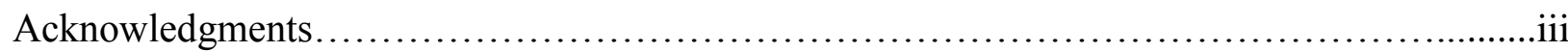

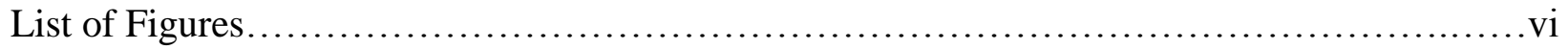

List of Tables..................................................................................

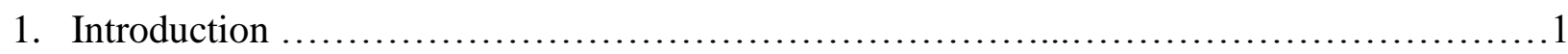

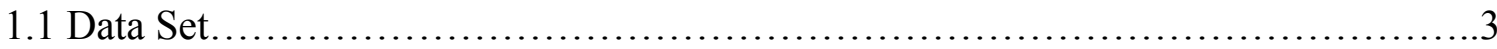

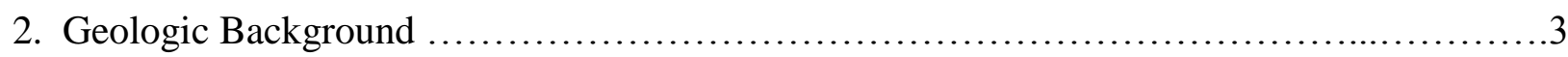

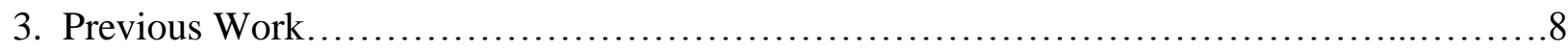

4. Seismic Texture and Other Attributes............................................... 9

4.1 Background and Previous Work..............................................10

4.2 Comparison with other attributes......................................... 12

4.3 Well Data Calibration vs. Volume Processing Applications.........................14

5. Preliminary Geologic Interpretations ................................................ 15

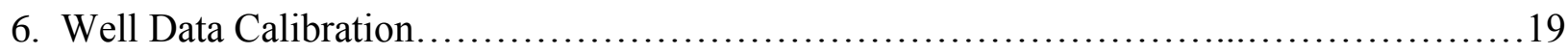

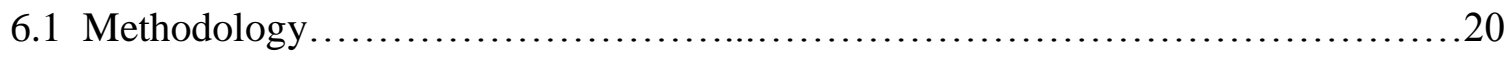

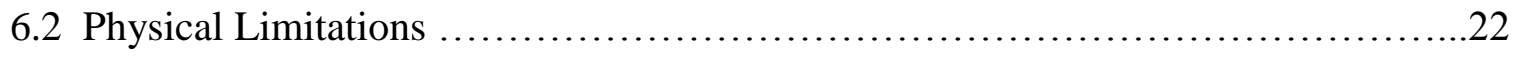

6.3 Calibration Results and Statistics..........................................22

6.4 Interpretations of Calibrations.......................................................

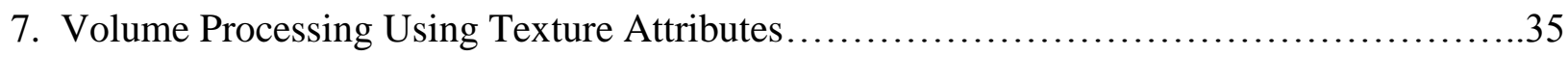

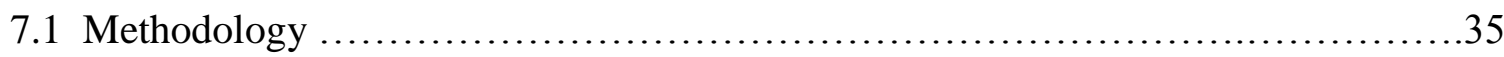

7.2 Volume Processing Results................................................ 36

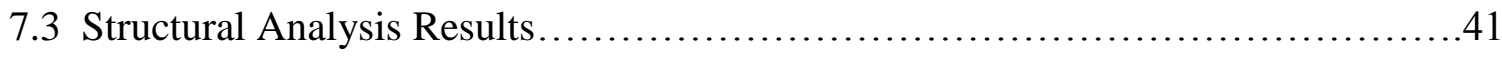

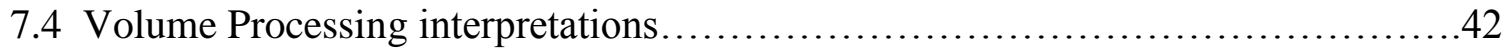


7.5 Structural Analysis Interpretations.

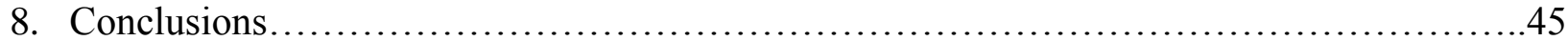

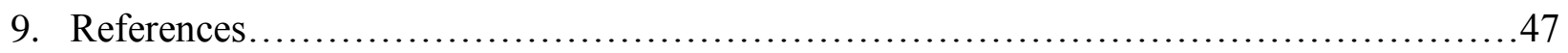




\section{LIST OF FIGURES}

Figure 1. Map of survey area with 10 wells and inset map of basin and location in PA.........2

Figure 2. Map of PA showing folds, faults, and physiographic provinces......................6

Figure 3. Map of PA showing paleo-extent of Salina salt basin............................6

Figure 4. Data to model waveform comparison and linear regression schematic..............11

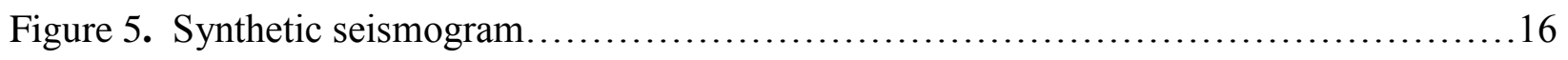

Figure 6. Time structure map of Marcellus Shale highlighting cross-strike features..............17

Figure 7. Interpreted Salina Salt time thickness map.................................. 19

Figure 8. Optimum model selection cross-plot.....................................23

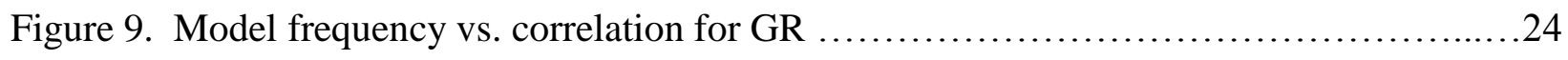

Figure 10. Optimal model selection cross plots used in cross-validation......................27

Figure 11. Property prediction map of porosity computed from texture data.................28

Figure 12. Property prediction map of gamma-ray computed from texture data showing location

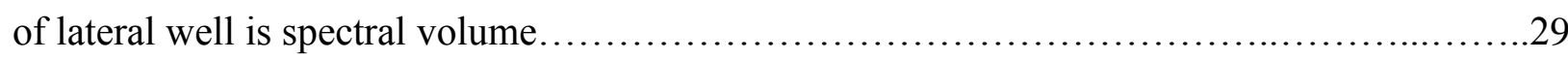

Figure 13. Comparison of logged properties and reservoir properties predicted from prediction

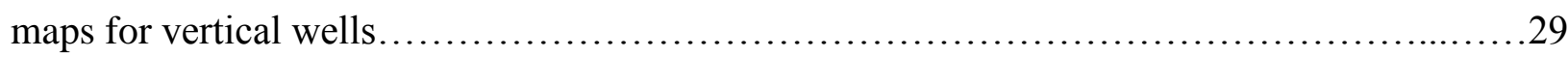

Figure 14. Property prediction map of gamma-ray computed from texture data.................30

Figure 15. Predicted and logged gamma-ray along length of a lateral well..................30

Figure 16. Optimal model selection cross-plot for improper gamma-ray data.................32

Figure 17. Optimal model selection cross-plot for improper porosity data....................33

Figure 18. Example cross sections from multiple volume processing results..................36

Figure 19: Faults picked from two texture volumes computed with different model

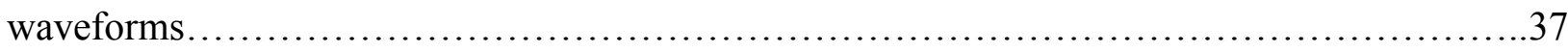


Figure 20. Single trace examples of volume processing outputs.......................... 38

Figure 21. Variance time slices computed from amplitude and texture attributes...............39

Figure 22. Curvature time slices computes from amplitude and texture attributes.............40

Figure 23. Comparison of cross-sections illustrating visual interpretation benefits of volume

processing using texture attributes.............................................. 40

Figure 24. Cross section of paired faults associated with thinning of underlying salt.............41 


\section{LIST OF TABLES}

Table 1. Attributes and variables used in multi-attribute models...........................25

Table 2. Example of forward selection output from multi-attribute model....................25

Table 3. Cross-validation error in predicting gamma-ray and porosity values from wells that are

removed from the optimum model selection process..................................26

Table 4. Average cross-validation error in predicting gamma-ray and porosity for all well

locations when respective wells are removed from optimum model selection process..........26 


\section{INTRODUCTION}

An amplitude texture refers to a characteristic pattern defined by the magnitude and variation of neighboring amplitude samples at a given location in an image space (Gao, 2011). There are multiple ways to characterize this pattern, one method being waveform model regression (WMR). Waveform model regression characterizes seismic amplitude texture by comparing portions of the seismic amplitude trace to model traces using linear least squared regression.

This research is an investigation into applying waveform model regression based seismic texture attributes, calibrating them with well data, and to enhance visualization of features in seismic data. A case study is provided on the use of texture attributes with 3D seismic and well data from the north-central Appalachian basin. Seismic texture is a little-known attribute that utilizes waveform model regression to detect differences in post-stack amplitude data. These efforts are meant to test texture attributes' viability and better understand what benefits and pitfalls exist when employing texture attributes for predicting petrophysical properties and enhancing interpretive capabilities.

To test WMR based texture attributes, a 3D post-stack seismic volume from northern Clearfield County of Pennsylvania is used (figure 1). This region is within the north-central Appalachian basin, an area that has seen hydrocarbon production in recent years due to the presence of the Marcellus Shale. The attribute methods used in the research are not dependent on the geologic regime or reservoir type, but for this study they will be applied to the Marcellus Shale with specific focus on attempting detecting local variations in reservoir properties and structural components that may be pertinent to local gas production. 


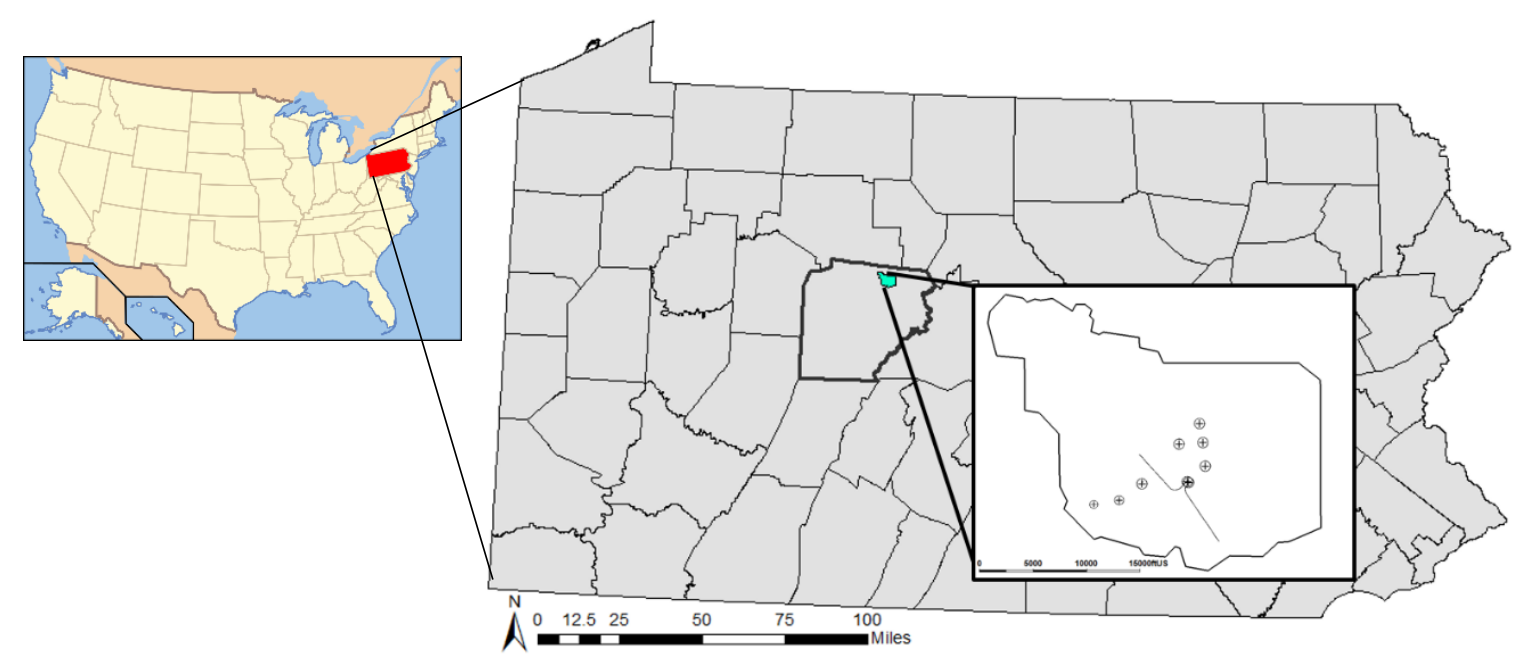

Figure 1: State of Pennsylvania (USA) illustrating location of $3 D$ survey used for study highlighting Clearfield County. Survey area map shows extent of seismic data and location of wells.

There are two general ways in which this research uses texture attributes. One way is to calibrate seismic data and well data, a commonly sought after technique in subsurface interpretation and prediction. The purpose of this research is to investigate the possibility of using seismic data to help estimate changes in rock properties away from the well locations, while using an attribute that requires few assumptions and little additional geologic information to compute. This research attempts to develop statistical relationships between texture attributes and well data that will aid in the estimation of rock properties for the extent of the 3D survey. In addition to testing this technology, some degree of success in this calibration can provide information about the reservoir that may be useful to wellbore placement in this region.

The other way in which WMR based texture attributes are used is to aid in structural interpretations. This approach is meant to enhance interpretive capabilities over using amplitude data or other attributes conventionally used in structure identification. Like the calibration based efforts of this research, using texture attributes for structural interpretation will provide 
information about the technological advantages, and information about the geologic structures in this region. Texture attributes are used alone and in conjunction will some other conventional geometric attributes.

\subsection{Data Set}

The data being used in this study includes a 16 square mile 3-D post stack seismic survey and data from 2 horizontal wells and 8 vertical wells, all located within the seismic survey. Of the 8 vertical wells, 7 have density, neutron porosity, gamma-ray, and some type of resistivity logs. Only one vertical well has a velocity log. The horizontal wells have gamma-ray, density, p-wave sonic, s-wave sonic in orthogonal directions, and computed mechanical property logs. Multiple attribute volumes are used for interpretation as well. These include texture processed structure volumes, a spectral volume, a variance volume, and a curvature volume.

\section{GEOLOGIC BACKGROUND}

The geographic setting of the study area used in this research is in Clearfield County, PA. This region of central Pennsylvania is located on the Appalachian Plateau physiographic province. Four main tectonic events have contributed to the geologic structure of the area. These tectonic events are the Grenville, Taconic, Acadian, and Alleghenian orogenies, with the latter three contributing to most of the structure and stratigraphy relevant to the scope of this work (Ver Straeten, 2010).

The Proterozoic Grenville orogeny is associated with the assembly of supercontinent Rodinia. Details about the configuration of the block-faulted Proterozoic basement are poorly understood (Ryder, 1992). Grenville orogenic events affected the crystalline basement on which 
the uppermost Cambrian and Paleozoic sedimentary rock accumulated (Sinha and Bartholomew, 1984). Existing interpretations show the northeast-trending, fault-controlled rifting as the dominant tectonic element of basement structure in Pennsylvania (Read, 1989; Gao et al., 2000). Uplift associated with the Taconic orogeny provided sediment source for the first major deposition in the Ordovician including major ramp carbonates and shallow marine facies making up the Trenton, Bald Eagle, and Juniata formations (Hatcher, 1989). The latter stages of the Taconic provided uplift and sediment source for the Silurian clastics (Laughery, 1999). The earliest phases of the Acadian orogeny brought about collision of Laurentia with multiple landmasses (Ver Straeten, 2010). Four major phases of Acadian tectonics dictate sedimentation from the early Devonian through early Mississippian. Devonian strata deposition including the Marcellus and structural changes in the underlying Salina and lower Helderberg Groups occurred during this time (Ettensohn, 1985).

The collision of Gondwana with Laurentia brought about the last major tectonic event effecting the Appalachian region, the Alleghenian orogeny. Major structural elements include northeast-southwest trending folds above a detachment sheet in the Silurian Salina Salt. Multiple fracture and joint sets connect the decollement near the Salina Salt to the upper Devonian Hamilton Group (Younes and Engelder, 1999).

On the Appalachian Plateau, multiple methods of shortening are proposed and multiple joints sets and fault trends have been identified. Using innovative technology to visualize what fractures are present in the region may lead to a better understanding of factors that influence hydrocarbon productivity. Some dominant structures on the Appalachian Plateau are a result of thin-skinned tectonic episodes including large scale detachment faults. In many cases, detachment is interpreted as occurring in upper Silurian units. Most detachment related 
deformation has been interpreted as westward verging thrust (Hatcher et al., 1988). Another Salina-related structural style that is observed in the Appalachian Plateau is kink band folding (Gillespie et al., 2014; Mount, 2014). Kink band folds observed on the Appalachian Plateau are controlled by stratigraphy. The upward extend is controlled by organic-rich shale units that act as a detachment, and a lower extent in the Salina detachment. Associated with higher order kink bands, are localized features, referred to as "pop-down" structures observed in the Salina Salt in 3-D seismic data in Pennsylvania on the Appalachian Plateau (Gillespie et al, 2014).

Joint sets have been extensively studied in the Appalachian basin, particularly regarding the Marcellus Shale. J1 is a northeast trending joint system that is present on the western side of the Allegheny structural front and is more closely spaced than the northwestern trending $\mathrm{J} 2$ joint set based on outcrops, core, and borehole images (Lash et al., 2004; Inks et al., 2014; Yuan et al., 2014). It is proposed in literature that both joint sets formed as natural hydraulic fractures during thermal maturation of organic matter (Engelder et al., 2009). Because of their proposed generation method and other observations of $\mathrm{J} 1$ and $\mathrm{J} 2$, they are expected to exist in black shales and units immediately above.

The study area for this research exists near the edge of the Silurian evaporite basin that has not been exposed, and is located near a distinct trend change in the Allegheny structural front (Ryder et al., 2007). At this region, some cross-strike faults have been mapped at the Onondaga interval (figure 2). The orientation of these faults is distinctly different from most faults and fold axis on the Appalachian Plateau (DCNR, Inks et al., 2014). 


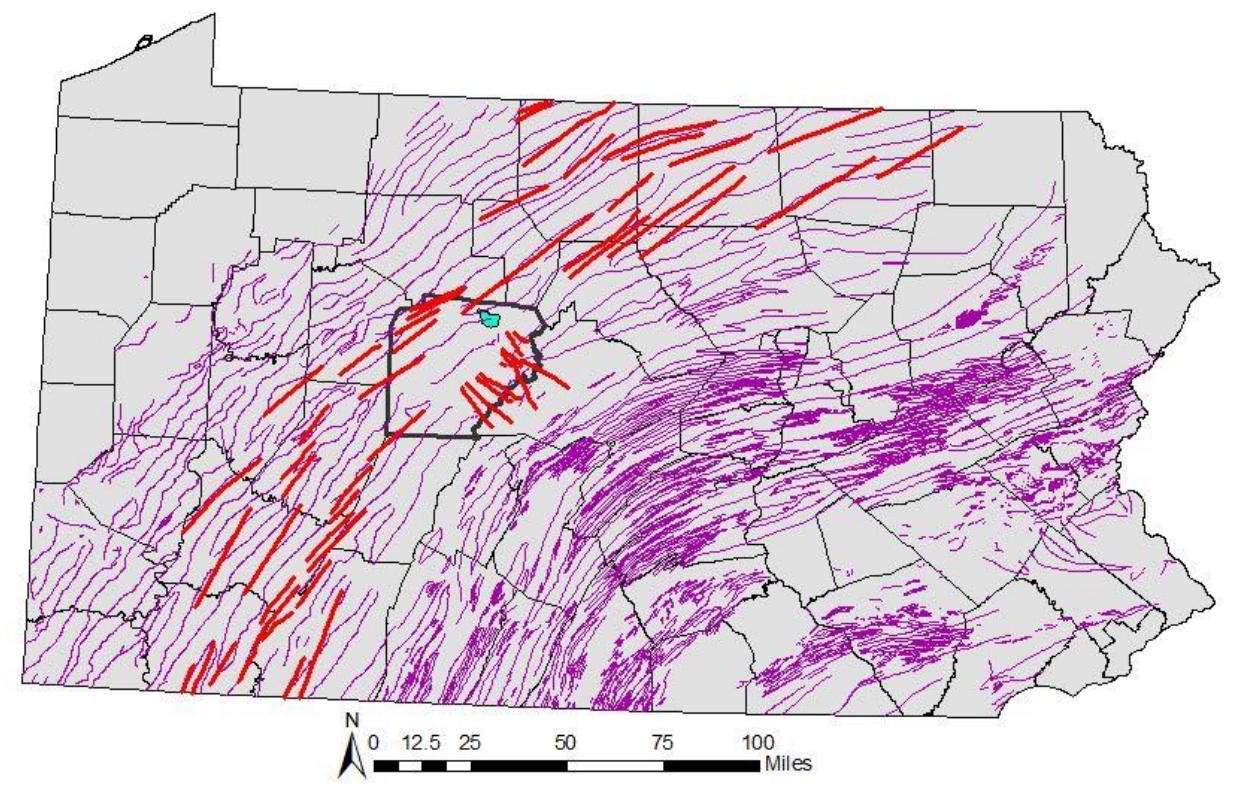

Figure 2: Map of Pennsylvania showing fold mapped fold axes (purple) and faults mapped at the Onondaga (red). Note the group of cross-strike faults just south of the survey area.

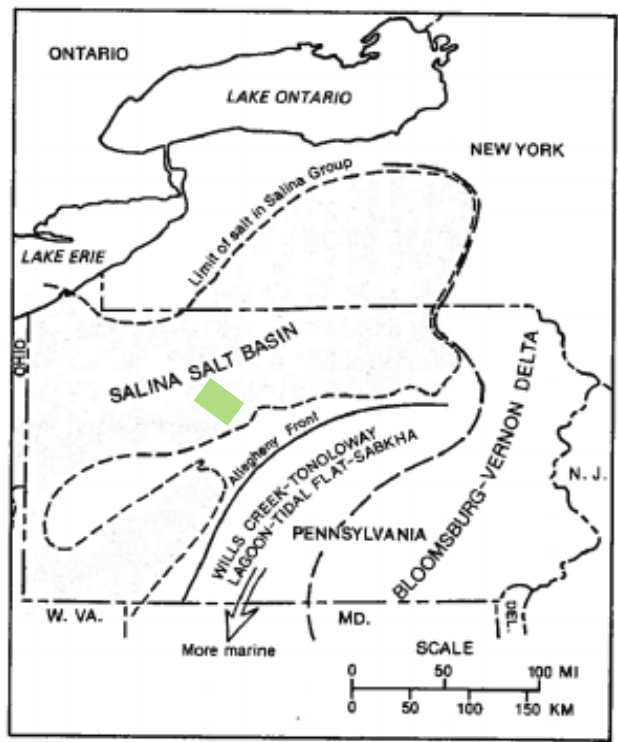

Figure 3: Approximate location of survey area in Clearfield County, PA indicated by exaggerated size green rectangle. Map shows the survey area existing within the extent of the Salina Salt basin during mid-Cayugan time. (Modified from Laughery, 1999) 
The case study provided in this research focuses on interpretations and testing technology on Silurian through upper Devonian stratigraphy. Three of the structural features (joints, kink bands, and detachments) are all observed in this interval and technologic limitations for calibration constrain the extent of testable data. The upper Silurian stratigraphy is of particular importance to as it contains evaporite units believed to act as a detachment in the central Appalachian basin (Ryder et al., 2008; Zagworski et al., 2012). The Salina Salt basin existed in northern and western Pennsylvania in the late Silurian and the research area exists near its southeastern edge (figure 3). The Salina Group evaporites are referred to as the Tonoloway, Wills Creek and Bloomsburg formations in outcrop, and have been referred to as Salina Group units A-H in the subsurface of central Pennsylvania and Western New York (Cotter and Inners. 1986). Salina Group halite ranges in thickness across the north-central part of Pennsylvania from less than 250 feet to over 500 feet. In the study area, it is believed to be up to 500 feet thick, with large thickness variations present (Mount, 2014). The base of the Silurian is marked by the Tuscarora formation. In the middle Silurian, the center of the northeast - southwest trending basin remained deeper than the margins which influenced the subsequent carbonate and shale deposition (Laughery, 1999).

Directly overlying the Tuscarora is the Rose Hill Shale, followed by the Keefer and Mifflintown Formations. All three of these formations are composed of marine mudrocks and interbedded carbonates. It has been suggested that the middle Silurian stratigraphy is a result of sea-level fluctuations on a submarine ramp that deepened from southeast to northwest and was deepest near the location of the present day structural front (Cotter and Inners, 1986).

In Pennsylvania, the earliest Devonian strata are Keyser, New Creek and Corriganville limestones (Harper, 1999). The Needmore Shale marks the transition from lower to middle 
Devonian in central Pennsylvania and underlies Huntersville Chert and Onondaga Limestone.

The Marcellus Shale is the reservoir interval of interest that overlies the Ondondaga Limestone.

The Marcellus is an organic-rich black shale that along with the overlying Mahantango

formation, make up the Hamilton Group. Above the Hamilton Group is the Tully Limestone

which marks the top of the interval of interest for this study. This research is not meant to be a

stratigraphic study, but the structural development of the region is affected by the stratigraphy, particularly weak detachment formations.

\section{PREVIOUS WORK}

Though texture is relatively new as a seismic attribute, it has been used in the past to enhance the capabilities of seismic interpretation. Texture attributes have been observed to better enhance structure and facies analysis than other attribute extraction algorithms (Gao, 2004, 2006; Chopra, 2005). Previously performed case studies provide examples of how the various texture analysis methods can be used for subsurface facies characterization (Gao, 2011).

Research has been done with this seismic data (Roberts, 2013; Bowers, 2014). Roberts' work involved using multiple conventional algorithms to identify the location of fractures and fracture swarms as it pertains to risk assessment and hydraulic fracturing. Some structural elements were identified, including cross strike lineaments interpreted as "damage zones" (Roberts, 2013). Roberts' paper posed hypothetical implications of the large "damage zones" if their nature was well understood, and this research project intends to provide an understanding of these features and their involvement with the underlying salt.

This seismic survey has also been used to develop a geomechanical model and analyze fracture stimulation data (Bowers, 2014). The identification of highly fractured regions within 
this seismic survey were identified using a geo-cellular model and strain attributes. These results can be compared to the identification of fractures identified in this research by texture attributes. Bowers' work proposes potential effects of the cross-strike and structure parallel features on production of lateral wells in the Marcellus, making the identification of their exact nature important for other areas within the basin. Applying texture attributes is intended to add to previous interpretations from this data by providing enhanced visibility. A quantitative calibration and petrophysical prediction has not been applied to this data.

\section{SEISMIC TEXTURE AND OTHER ATTRIBUTES}

Seismic attributes are any quantitative measure of a seismic character of interest (Chopra and Marfurt, 2005). Attributes can be classified in several ways, but can be broken into two main groups based on their function. Attributes that are used to enhance the visibility of structural features in the seismic data or on seismic horizons are geometric attributes. These include attributes such as dip, azimuth, curvature, and variance. Attributes that are believed to relate to physical parameters of the subsurface such as mechanical properties and lithologic characteristics are categorized as physical attributes. These are typically related to the seismic trace and include amplitude, phase, and frequency (Taner et al., 1994 and Chopra and Marfurt, 2005).

In 3D seismic image analysis, seismic texture refers to the internal configuration of amplitude samples within a small zone in the 3D space (Gao, 2004, 2006, 2011). It is difficult to categorize seismic texture attributes because their use varies depending on their objective. As a geometric attribute, texture is used in what is referred to as volume processing applications. The other method that texture attributes are used is to assist in rock property estimation and 
calibration with well data. This would be categorized as a physical attribute. Waveform model regression based texture is relatively underused and poorly known. The purpose of this research is to provide a case study using these attributes both in a physical and geometric sense to assess its viability in both cases.

\subsection{Background and Previous Work}

WMR based texture attributes have had limited use in the past, but there has been some documented cases of its effectiveness (Gao, 2003, 2004, 2011). Dynamic waveform model regression specifically was documented in Gao's 2011 research. Rather than use a static model waveform like those used in structural volume processing, the model waveform has adaptive phase, frequency, and maximum amplitude. Gao's research using the dynamic waveform method showed reduced structural interference, and proposed the use of an iteratively changing model waveform for reservoir property calibration. This research intends to apply both the use of a static model waveform for seismic visualization and dynamic model waveform for calibration with well data.

Whether being used as a physical attribute or a geometric attribute, the basis for computing seismic texture is similar. Each lateral coordinate $(\mathrm{x}, \mathrm{y})$ is defined by single seismic trace in a post stack volume, considered to be a time series defined by two-way travel time and amplitude. Each trace is considered independent of those adjacent to it, and is compared to a model waveform. Describing the differences between seismic traces is the purpose of performing waveform model regression and is outlined by the following steps (figure 4) 
1. Retrieval of amplitude data defined by $n$ samples at $(\mathrm{x}, \mathrm{y}, \mathrm{z}) \mathbf{D}_{\mathbf{i}}(\mathrm{x}, \mathrm{y}, \mathrm{z})(\mathrm{i}=1 \ldots n)$

2. Construction of a model texture with defined phase and frequency $\left(\mathbf{M}_{\mathbf{i}}\right)(\mathrm{i}=1 \ldots n)$

3. Linear least-squares regression between model and data $\left(\mathbf{M}_{\mathbf{i}} \sim \mathbf{D}_{\mathbf{i}}\right)(\mathrm{x}, \mathrm{y}, \mathrm{z})$

4. Calculate absolute gradient or correlation coefficient of regression line

5. Move to next sample location $(\mathrm{x}, \mathrm{y}, \mathrm{z})$

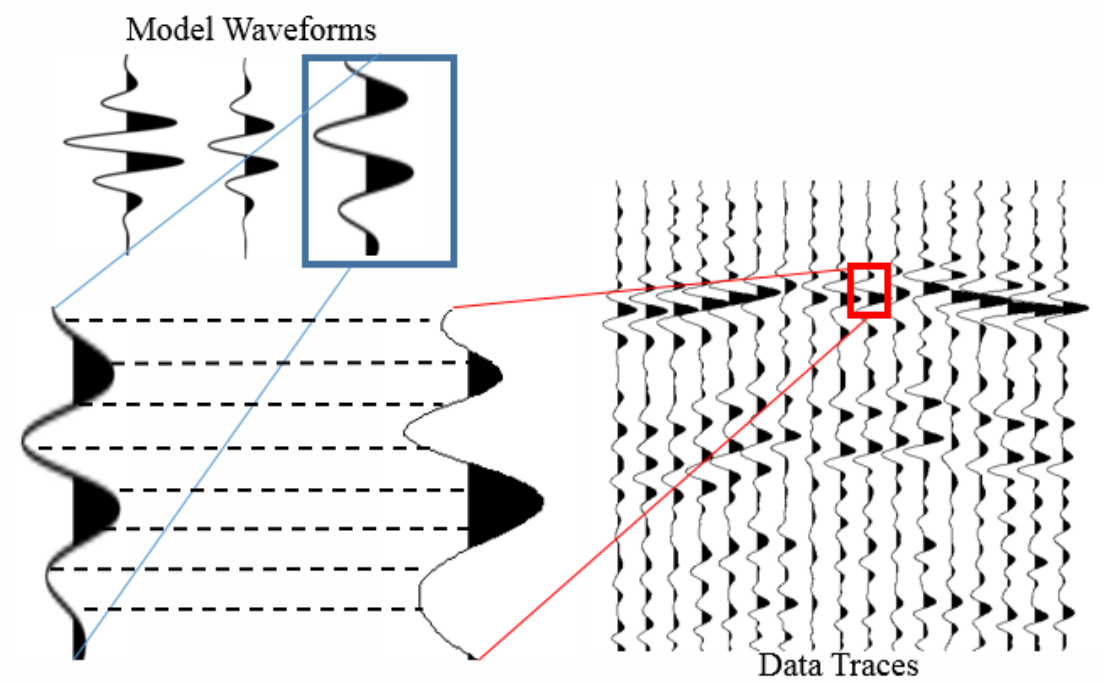

Figure 4: Schematic illustrating waveform model regression using model data traces. Each pair of samples (connected by dotted lines) are used in linear least squared regression and the slope of the line of best fit is the output used for texture attributes.

These basic steps can be altered or have additional steps added to them depending on the goals of the interpretation. The most basic component of waveform model regression is to compare input data, in this case amplitude, to some model data, and analyze the regression (output) between them. The output is indicative of a relationship between the input data and the model. Each regression slope (output) needs to have a singular defined location in space (x, y, $\mathrm{z}$ ), for it to be useful for interpretation. There are multiple ways to assign this $(\mathrm{x}, \mathrm{y}, \mathrm{z})$ location that depend on how the attribute is being used, but regardless of its use there is one concept that should remain apparent. The input data defined by multiple $(n)$ samples is defined by texture as 
a single output value, thus the output cannot occupy the same space $(\mathrm{x}, \mathrm{y}, \mathrm{z})$ as the input. The location of the output corresponds to the center $(\mathrm{z})$ of the $n$ samples of the input, and maintains the same $(\mathrm{x}, \mathrm{y})$ position as the input. In any applications of the attribute, this would lead to less densely populated data in the (z) dimension, essentially populating an output volume defined by $1 / n$ the amount of data as the input. This issue is reconciled in two different ways, depending on the desired use of the attribute. Output data is not less densely populated than input data in either the volume processing or the well data calibration applications.

\subsection{Comparison with Other Attributes}

There exist a large and growing number of seismic attributes that can be used for structural interpretations and reservoir property analysis. Some interpreters believe that there are in some cases, too many attributes being employed on the same data. When performing calibration, overtraining of models may occur (Barnes, 2006; AlBinHassan and Wang, 2011; Bagheri and Riahi, 2015). One potential advantage of using WMR based texture is that it is a single, simple to compute attribute that is affected by all components of the seismic trace. In addition, it is hypothesized that it can be used to discriminate adjacent traces without needing to compare adjacent traces to one another as some geometric attributes do ( $\mathrm{Li}$ and $\mathrm{Lu}, 2014$; Koson et al., 2014).

To detect discontinuities, seismic texture utilizes a model waveform to make discrepancies between adjacent traces easier to visualize. This difference is critical in its comparison with other attributes that help visualize discontinuities. For example, coherency and chaos attributes utilize differences in amplitude or dip to detect discontinuities (Koson et al., 2014). This is useful for highlighting discrete features as being different, but not to what degree 
or the nature of the difference. WMR based texture utilizes a model waveform to do a soft calibration, and the resulting output highlights not only subtle discontinuities, but gives some information to how adjacent traces differ. This also reduces to the need for other attributes in addition to coherency, as coherency volumes/slices show little data outside of regions of high variance (Gao, 2011; $\mathrm{Li}$ and $\mathrm{Lu}, 2014)$.

There are attributes used to estimate petrophysical properties that have an obvious rock physics basis for anticipating relationships such as inverted acoustic impedance and mechanical properties (Schultz et al., 1994, Bosch et al, 2010). Texture attributes however, rely on a datadriven approach to develop statistical relationships with rock properties, as many other attributes do. Attributes such as instantaneous frequency, amplitude heterogeneity, instantaneous phase, and amplitude envelope have been used in data-driven statistical approaches to predict rock properties (Todorov et al., 1998; Schultz et al., 1994; Pederson et al., 1996). All features of the seismic signal are directly caused by rock physics phenomena (Schultz, 1994). Because this is the case, when doing data-driven prediction, it may be more useful to use an attribute that does not eliminate components of the trace such as frequency, phase, or amplitude alone. For this reason, it is hypothesized that texture attributes may yield significant statistical relationships with logged properties.

In data-driven property prediction, it is sometimes necessary to use multiple attributes to perform a multivariate model or to determine which attributes have a statistical relationship with logged properties (Todorov et al., 1998; Hampson et al, 2000). This is one component that is absent from the proposed approach of using only texture attributes. It is theorized that by varying the model waveform, that a significant relationship with well-log properties may be achieved without the use of other attributes. 


\subsection{Well Data Calibration vs. Volume Processing Applications}

To perform well data calibration to texture data, a specific interval of the seismic data must be selected. The goal of the horizon based algorithm is to perform waveform model regression on the amplitude data within a window centered on the Marcellus using many different model waveforms. The goal of this operation is to determine the model waveform that results in attributes computed at wellbore locations that correlate best with petrophysical properties logged at respective wells.

The reservoir centered application has limited, but effective uses. It utilizes a spectral volume, which is only good for very general visual interpretations. It is however appropriate for examining how altering the model waveform affects the resulting texture data correlations with reservoir properties. To apply many model waveforms, would result in a large number of individual attribute surfaces that would need interpretation. It is impractical analyze these surfaces and attempt to visualize them in the time or depth domain. Visualizing this data in a traditional sense has limited, if any meaning to an interpreter, but it allows for large number of attribute surfaces to be tested against well properties with relative computational simplicity.

As opposed to the horizon based application of texture attributes, the volume processing application is utilized best for data visualization. Volume processing applications are limited by the number of attribute volumes one could practically interpret. The method for computing the texture attribute remains the same for either application. The difference is that the volume processing applied in this research, uses one model waveform to transform amplitude volumes to texture volumes, maintaining the input's dimensionality. Therefore, it can be interpreted with relative ease. The purpose of volume processing for this research is to aid in the interpretation of 
geologic structure, while the purpose of the horizon based application is to aid in well calibration.

\section{PRELIMINARY GEOLOGIC INTERPRETATIONS}

To assess texture attribute effectiveness, conventional geologic interpretations must be performed on the seismic data. This includes, horizon mapping, creation of synthetic seismograms, domain conversions, and structural interpretations. General geologic reconnaissance provides features for further investigation with attribute data.

To begin the geologic interpretation, the stratigraphic interval of interest must be located in the seismic data. To aid in doing this, a synthetic seismogram is used. Only one of the vertical wells has a sonic log that exists from 3,100 feet to 7,340 feet. The slowness log (inverse of velocity) is used in conjunction with the density log to create a synthetic seismic trace. The density and velocity logs are used to create an acoustic impedance log, which is used to make a reflection coefficient series. A $28 \mathrm{hz}$, fixed frequency wavelet is convolved with the reflection coefficient series to create the synthetic seismic trace. A $28 \mathrm{hz}$ wavelet is used because that is the dominant frequency of the amplitude data at the reservoir interval. Without check-shots, a full vertical sonic log, and data collection differences between seismic data and the well logs, the synthetic seismogram is not guaranteed to match with the seismic data in the region that the logs are present (Ewing, 2001). By stretching the synthetic seismic, a general match can be accomplished between the synthetic and seismic data at the location of the well (figure 5A). Lithologic tops were picked using gamma ray logs and for most of the wells in this study, driller's picks were provided. These lithologic tops are then matched with reflections for horizon interpretation (figure 5B). 


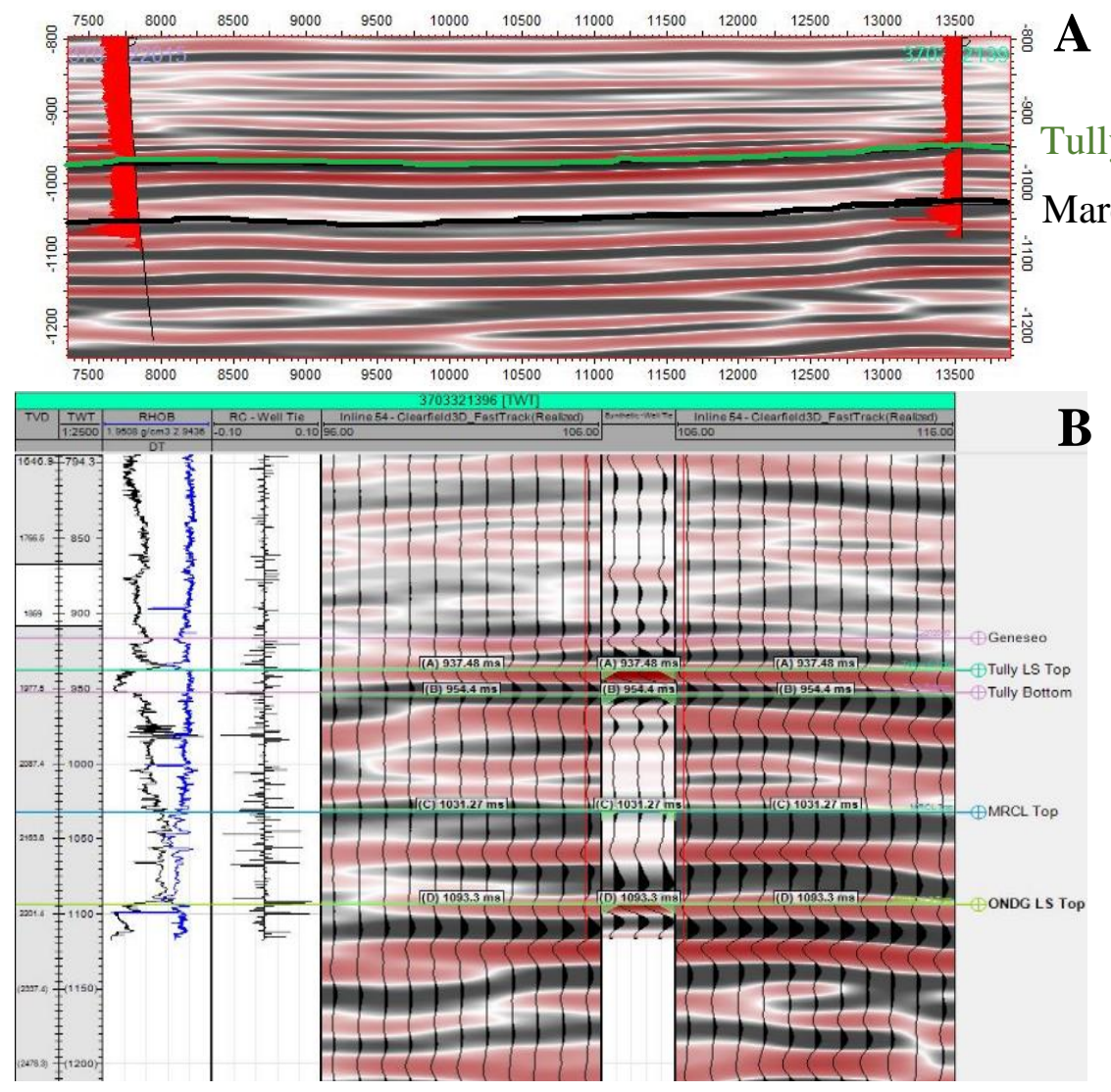

Figure 5: Synthetic seismic trace made using velocity and density matched with adjacent seismic traces. Figure 5A shows the time-depth relationship created from the synthetic seismic generation applied to other wells to convert the wells to the time domain. Once in the time domain, lithologic tops were associated with seismic reflectors. Log shown in figure 5B is gamma-ray.

Fractures and horizons were interpreted from the amplitude data to provide a general geologic reconnaissance before attributes were used. Horizons were interpreted by following continuous reflectors in the seismic data and observing the log data converted to the time domain. The lithologic tops that are interpreted include top and bottom of the Salina, Marcellus, Tully, and the top of the Onondaga and Genneseo.

Multiple types of structural features are interpreted to be present within the survey area. Using the amplitude data, fractures are interpreted as discontinuities in reflectors. There are interpreted structure parallel lineaments that strike approximately $30^{\circ}-50^{\circ}$ northeast. It is 
difficult to interpret exactly what type of features these are using amplitude data, but the majority of the northeast trending features are limited to a vertical extent from the top of the Salina to the middle Marcellus. The other set of lineaments interpreted in the amplitude data are structureperpendicular and trend at roughly $315^{\circ}$ and $345^{\circ}$ northwest. These features differ greatly in their seismic expression from the structure-parallel lineaments. The northwest trending features have a much greater vertical extent, spanning from above the Tully Limestone, to far below the base of the Salina. The lower extent is approximately 0.5 seconds (TWT) below base of the Salina. These lineaments are also best expressed in terms of vertical offset of reflectors, similar to narrow anticlines (Figure 6). The majority of anticlinal features and large scale fractures in postSilurian strata are oriented northeast-southwest, as opposed to these northwest striking features (Mount, 2014). Both feature types will be discussed in more depth when analyzing texture enhanced attribute volumes in section 7.3.

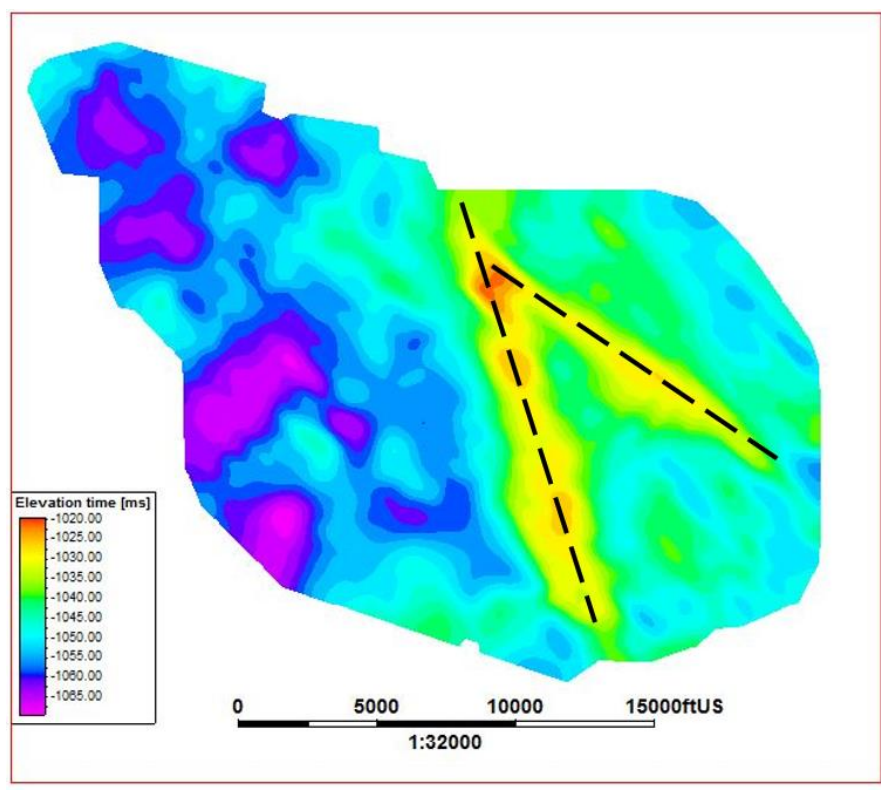

Figure 6: Time structure map for the top of the Marcellus Shale highlighting cross strike features associated with linear structural highs. 
Using the amplitude data, preliminary observations regarding the salt detachment can be made. Of interest are thickness changes, and structural expression of strata above and below the salt. When observing the isochore map for the Salina interval, most prominent thickness changes have a northeast trend and correspond to interpreted discontinuities in the overlying rock (figure 7). Multiple cases of this pattern exist within the survey area, with the overlying discontinuities converging upward near the top of the Marcellus. It is difficult to determine the exact nature of the features in this area and whether or not they are salt facilitated because the vertical extent of many of the fractures cannot be determined using amplitude data.

There is another pattern of salt thickness change that is less prominent, but that also coincides with lineaments seen in overlying strata. Two large northwest striking features with large vertical extent are apparent on the salt thickness map, but less so than the northeast striking features. The northwest striking features do not terminate, either upper or lower extent, in the Salina Group. The preliminary geologic reconnaissance provides useful information about the geologic structure within the survey and points of interest that can be used in testing the effectiveness of WMR based texture attributes. 


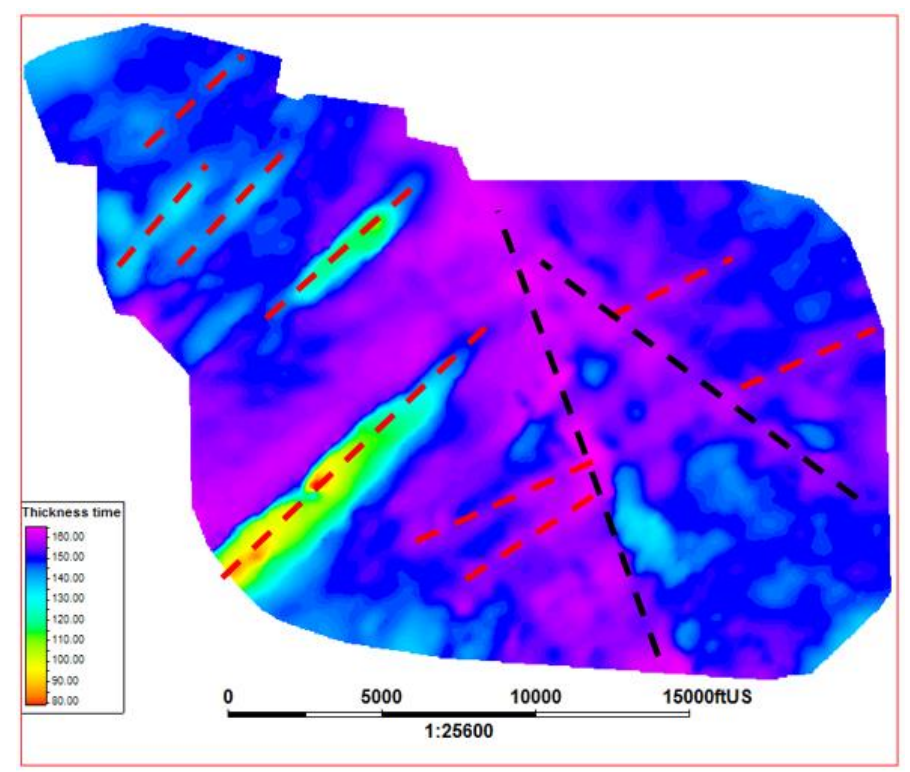

Figure 7: Time thickness map of the Salina Salt. Two prominent trends exist in thickness changes that are associated with the structure-parallel features that terminate in the Salina, and the Northwest trending faults that are interpreted as not terminating in the Salina detachment.

\section{WELL DATA CALIBRATION}

It is of interest to many interpreters to estimate reservoir properties in inter-well areas, particularly when seismic data is present. This can be done using a variety of techniques including inversion, machine learning, and multi-variable correlations, each with their own rockphysics or statistical methods (Bosch et al., 2010; Hampson et al., 2000; Bagheri and Riahi, 2015). The challenges of this research include a small number of wells within the seismic volume, no obvious rock-physics relationship with the proposed attribute, and a lack of precedent for using this variable for reservoir property calibration. To overcome some of these challenges, statistical approaches are taken to investigate the calibration efforts, and other conventional attributes will be incorporated for comparison to texture attributes. 


\subsection{Well-data Calibration Methodology}

The basics of computing waveform model regression is outlined in section 4.1. Based on the regular waveform model regression algorithm, a dynamic waveform model regression algorithm using multiple model waveforms are used to generate a spectral 3-D volume (Gao 2011, 2017). To create the volume, an interpreted horizon must be selected. For this application, a horizon at the middle of the Marcellus shale is used. All of the waveform model regression calculations will be centered in the z-position around this horizon. To populate the spectral volume, a number of model waveforms equivalent to the z-dimension's extent of the spectral volume are needed. These waveforms are defined by the vertical window size (number of amplitude samples), and the frequency of model waveform.

By varying the size and frequency of the model waveform, an entirely different output can be created. Cross-checking the extremely large number of possible output volumes (possible due to an extremely large number of potential model waveforms) to the wells within the survey would be computationally impractical, because this process is not currently automatic. Instead, a large number of different model waveforms will be used to target the Marcellus shale reservoir, and a property prediction will be performed on only the reservoir interval.

Each model waveform has a specific window size and frequency combination that corresponds to the vertical position in the spectral volume. There are 15 window sizes used, and for each window size, 32 frequencies are used, making for a total of 480 model waveforms. The z-position of the output data of the spectral volume is first ordered by window size, such that the first 32 z-positions use the smallest window, the following 32 z-positions (32-63) use the second largest window size, and so on. Within each group of 32 slices with the same window size, the z-position corresponds to increasing frequency of the model waveform. The window sizes range 
from 5 samples $(10 \mathrm{~ms})$ to 33 samples $(66 \mathrm{~ms})$, and the frequency of the models are defined by the number of cosine cycles within each corresponding window from a minimum of 1 cycle to a maximum of 4 cycles. This corresponds to frequency by the following equation:

$$
\text { Frequency } \left.(\text { model })=\left(1+\left(p^{*} .09375\right)\right) / 2 n\right) \text {, }
$$

In which $p$ is the iteration (1-32) within the corresponding window size, and $n$ is the number of samples defining the model waveform (5-33). Designing the horizon-based volume in this way facilitates the determination of the optimal model's frequency and size.

Determining the optimum model waveform is determined by analyzing which window sizes and frequencies of the models correspond to the highest correlation with logged reservoir properties. Texture outputs from all 480 models are compared to 3 up-scaled measures of neutron porosity and gamma-ray at each vertical well location. The optimum model waveform derived texture attributes are then compared to other conventional attributes individually and in a multi-attribute model to determine their significance compared to other attributes. To test the equations that are made to estimate reservoir properties from texture attributes, cross-validation is used by removing each well, one at a time, and attempting to predict the reservoir properties at individual well locations. Finally, the equations will be used to generate reservoir property maps and data from those maps are validated against vertical and horizontal well data. 


\subsection{Physical Limitations}

The primary concern when performing any data-driven seismic calibration is the lack of resolution of seismic data. It is impractical to expect to detect vertical variations of reservoir properties within the Marcellus using texture attributes. The post-stack seismic data being used has a $2 \mathrm{~ms}$ sampling rate, and one vertical position the reservoir is represented by about 20-25 amplitude samples. This reduces the ability to calibrate texture at a fine vertical interval within the reservoir. Instead, the reservoir properties must be up-scaled so that an interval of logged data is represented by a single value. For calibration purposes, the reservoir properties are upscaled to a 10 foot, 20 foot, and entire reservoir interval averages.

The primary physical constraint for calibrating texture attributes is that there is no obvious rock physics relationship between reservoir properties and texture. This is not an unprecedented issue as most data-driven property prediction relies on statistical relationships between seismic data and rock properties (Todorov et al, 1998). When performing a calibration using empirical relationships, it is advantageous to incorporate as much data as possible. With only seven vertical wells, the lack of physical data presents challenges in building robust prediction models and creating training data sets.

\subsection{Calibration Results and Statistics}

The spectral volume was generated, and the data along each vertical well path was extracted. Seven vertical wells have a resulting extracted attribute trace and are used in determining an optimum model waveform. Figure 8 illustrates example results for how the optimum model waveform selection can be interpreted. Each reservoir property has its own relationship with the output associated with each model waveform. For each reservoir property, 
an optimum model waveform is determined from plots such as these. To aid in the optimum model selection, model frequency versus correlation $\left(\mathrm{r}^{2}\right)$ cross-plots are produced. Included in figure 9, these cross-plots provide information about which model waveform frequencies are associated with highly strong correlations to well data. These plots often result in a small range of frequency for preferable models, or models with high correlation strength, when compared with well data.

Figure 8 illustrates the relationship between model waveform parameters and correlation strength for the gamma-ray at the entire reservoir thickness. Similar plots are generated for porosity to assist in determining the optimum model for use in porosity prediction.

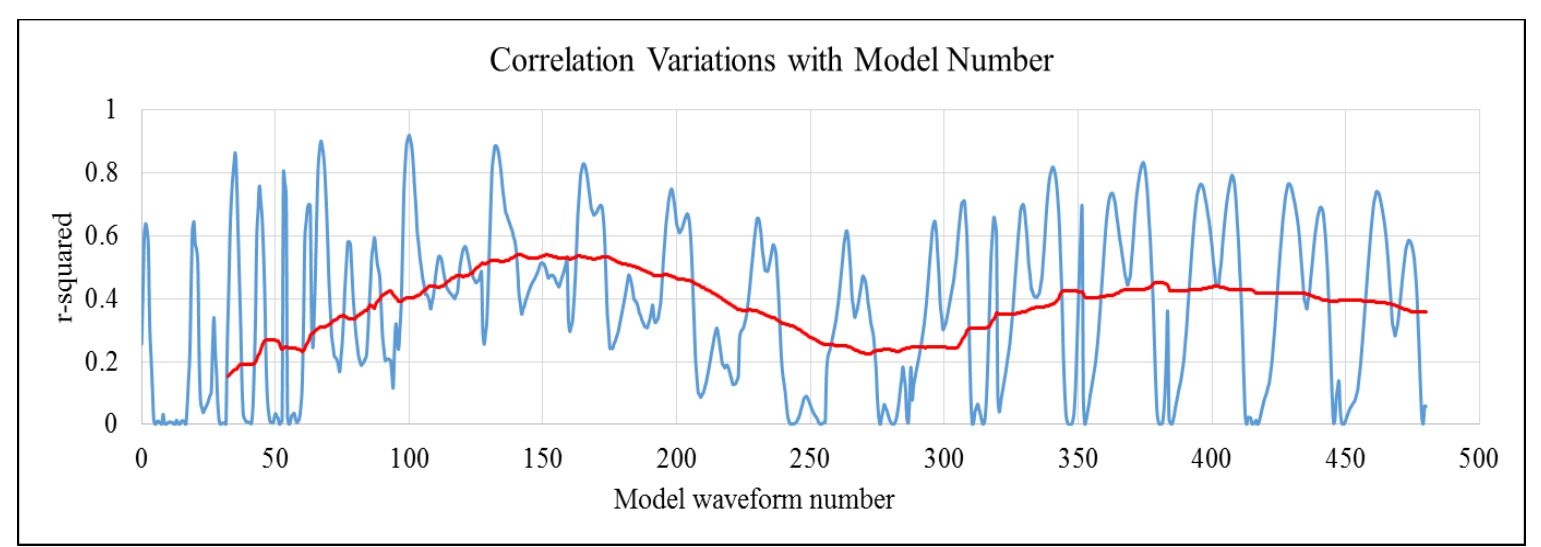

Figure 8: Correlation results between all 7 vertical wells with logged gamma-ray and the texture attribute data from the horizon-based volume. The reservoir property associated with this plot is the up-scaled GR for the entire reservoir interval. The blue line represents individual model number to correlation points. The red line is a 32-point moving average, dictated by the 32 models per window size. 


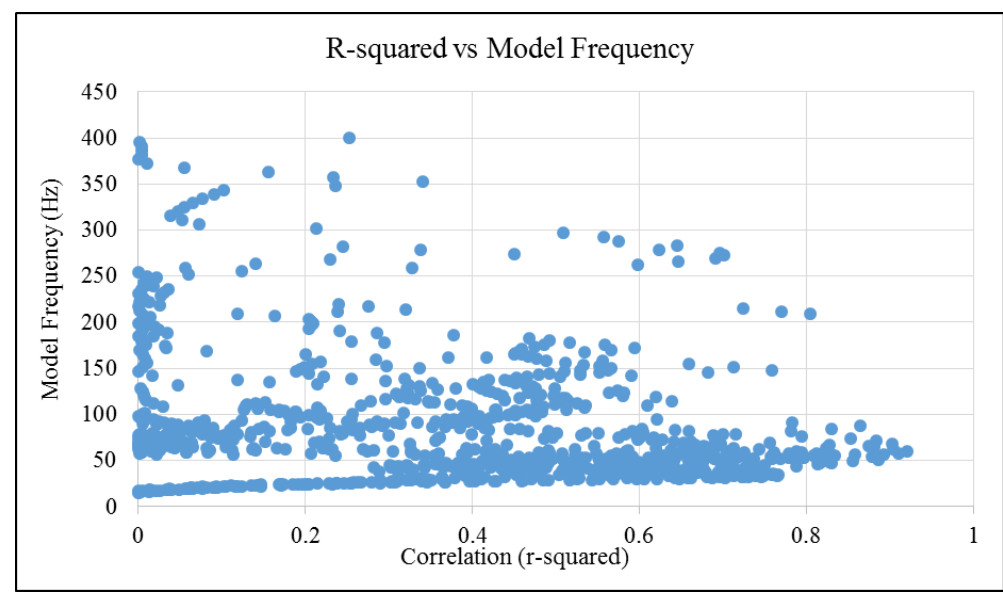

Figure 9: Results pertaining to the $r^{2}$ values and corresponding model frequencies for the correlation between texture attribute data and the gamma-ray averaged from the entire thickness of the Marcellus Shale.

High $\mathrm{r}^{2}$ values (up to 0.93 ) are observed between texture attributes and reservoir properties, but to further investigate its viability as a predicting attribute, texture is compared with other attributes in forward selection and adjusted $r^{2}$ statistical models. A forward selection model building process was applied to all attributes in table 1 and each of the 6 up-scaled reservoir properties. This is performed to test how well texture attributes can predict reservoir properties alone and how significant empirical relationship developed using textures are compared to the significance of a multi-attribute model. Forward selection also provides an equation to predict reservoir properties using texture attributes alone or more complex equations to predict reservoir properties using multiple attributes. The results in table 2 , include only the first 4 steps of a nine step forward selection process, but the model continues to degrade with the inclusion of additional attributes. It is important to note that the probability of getting F-scores as high as this using models with texture are very low, and thus the sum of squares (a measure of predicted vs. actual gamma-ray) is also low. These results are indicative of a model that accurately predicts the reservoir properties. Six forward selection processes were performed, but each showed similar results to those in table 2. 


\begin{tabular}{|l|l|}
\hline Attributes Used in Multi-attribute Models & Reservoir Properties \\
\hline Amplitude Envelope & Middle 10 feet Gamma-ray \\
\hline Optimum Model Waveform Texture & Middle 20 feet Gamma-ray \\
\hline Amplitude Variance & Entire Reservoir Gamma-ray \\
\hline RMS Amplitude & Middle 10 feet Neutron Porosity \\
\hline Instantaneous Frequency & Middle 20 feet Neutron Porosity \\
\hline Average Absolute Amplitude & Entire Reservoir Neutron Porosity \\
\hline Trace Derivative & \\
\hline Absolute Trace Derivative & \\
\hline Dominant Frequency & \\
\hline
\end{tabular}

Table 1: List of attributes and reservoir properties used in multi-attribute models. The 6 reservoir properties are the same logged data that is used in selecting optimum models and in all reservoir property prediction applications included in this study. Seismic attributes other than "Optimum Model Waveform Texture," are selected based on popularity in literature for use in attribute calibration, and for scientific inquiry based on quantification of texture attributes.

\begin{tabular}{|c|c|c|c|}
\hline \multicolumn{4}{|c|}{ FORWARD MODEL SELECTION FOR GR (MIDDLE $10 \mathrm{FT}$ ) } \\
\hline \multicolumn{4}{|c|}{ Step 1} \\
\hline Variable & Parameter Estimate & F-Value & $\operatorname{Pr}>\mathrm{F}$ \\
\hline Intercept & 323.315 & & \\
\hline Optimal Model Texture & -45590 & 47.16 & 0.001 \\
\hline \multicolumn{4}{|c|}{ Step 2} \\
\hline Variable & Parameter Estimate & F-Value & $\operatorname{Pr}>\mathrm{F}$ \\
\hline Intercept & 292.442 & & \\
\hline Optimal Model Texture & -38500 & 23.5 & 0.0084 \\
\hline RMS Amplitude & 36.383 & 1.94 & 0.2365 \\
\hline Total Model (ANOVA) & & 28.96 & 0.0042 \\
\hline \multicolumn{4}{|c|}{ Step 3} \\
\hline Variable & Parameter Estimate & F-Value & $\operatorname{Pr}>\mathrm{F}$ \\
\hline Intercept & 254.907 & & \\
\hline Optimal Model Texture & -28591 & 21.86 & 0.0185 \\
\hline Trace Derivative & -87.487 & 7.43 & 0.0722 \\
\hline RMS Amplitude & 84.487 & 12.44 & 0.0387 \\
\hline Total Model (ANOVA) & & 52.83 & 0.0043 \\
\hline \multicolumn{4}{|c|}{ Step 4} \\
\hline Variable & Parameter Estimate & F-Value & $\operatorname{Pr}>\mathrm{F}$ \\
\hline Intercept & 242.215 & & \\
\hline Optimal Model Texture & -35927 & 60.78 & 0.0161 \\
\hline Trace Derivative & -117.656 & 27.8 & 0.0341 \\
\hline Instantaneous Frequenc & 84.487 & 6.59 & 0.1242 \\
\hline RMS Amplitude & 88.987 & 39.18 & 0.0246 \\
\hline Total Model (ANOVA) & & 115.07 & 0.0086 \\
\hline
\end{tabular}

Table 2: Example results from the forward selection model. These results are specifically for the gamma ray of the middle 10 feet of the Marcellus. At each step, the empirical relationship is assessed and an overall model F-value computed. Based on ANOVA and corresponding F-values, the best model is when only Optimal Model Texture is used, though RMS amplitude also has considerably high F-values. 


\begin{tabular}{|c|c|c|c|c|c|c|}
\hline Without well \# & GR \%ERROR & GR (10) \%ERROR & GR(20) \%ERROR & NPHI \%ERROR & NPHI(10) \%ERROR & NPHI(20) \%ERROR \\
\hline 1 & 6.680 & 4.114 & 2.932 & 1.569 & 7.194 & 2.579 \\
\hline 2 & 9.029 & 1.727 & 1.681 & 1.361 & 7.030 & 6.973 \\
\hline 3 & 0.487 & 1.863 & 2.241 & 2.975 & 8.332 & 4.053 \\
\hline 4 & 6.390 & 8.650 & 7.816 & 6.195 & 6.983 & 4.318 \\
\hline 5 & 10.243 & 8.138 & 7.367 & 0.679 & 3.777 & 2.798 \\
\hline 6 & 9.151 & 13.130 & 10.698 & 5.163 & 11.110 & 7.436 \\
\hline 7 & 5.788 & 3.031 & 2.000 & 8.359 & 2.094 & 7.221 \\
\hline Averages & $\mathbf{6 . 8 2 4}$ & $\mathbf{5 . 8 0 8}$ & $\mathbf{4 . 9 6 2}$ & $\mathbf{3 . 7 5 7}$ & $\mathbf{6 . 6 4 6}$ & $\mathbf{5 . 0 5 4}$ \\
\hline
\end{tabular}

Table 3: Error in predicting the reservoir properties from well-data using optimum model texture. Each error is for the predicting data at the well location that was removed from the derivation of the best fit equation. Reservoir properties with (10) or (20) are the middle 10 feet and 20 feet up-scaled values respectively.

\begin{tabular}{|c|c|c|c|c|c|c|}
\hline Without well \# & GR \%ERROR & GR (10) \%ERROR & GR(20) \%ERROR & NPHI \%ERROR & NPHI(10) \%ERROR & NPHI(20) \%ERROR \\
\hline 1 & 5.427 & 4.605 & 3.908 & 2.882 & 5.762 & 4.265 \\
\hline 2 & 4.644 & 4.494 & 3.857 & 3.975 & 5.673 & 4.837 \\
\hline 3 & 4.993 & 4.487 & 3.873 & 3.935 & 6.366 & 5.196 \\
\hline 4 & 5.006 & 4.918 & 4.236 & 4.032 & 5.788 & 4.806 \\
\hline 5 & 5.163 & 4.305 & 3.650 & 4.386 & 6.192 & 5.424 \\
\hline 6 & 5.095 & 4.439 & 3.848 & 3.806 & 4.244 & 3.820 \\
\hline 7 & 5.237 & 4.472 & 3.878 & 4.137 & 4.990 & 5.326 \\
\hline N/A & 4.961 & 4.392 & 3.756 & 3.975 & 5.701 & 4.837 \\
\hline Averages & $\mathbf{5 . 0 8 1}$ & $\mathbf{4 . 5 3 1}$ & $\mathbf{3 . 8 9 3}$ & $\mathbf{3 . 8 7 9}$ & $\mathbf{5 . 5 7 4}$ & $\mathbf{4 . 8 1 1}$ \\
\hline
\end{tabular}

Table 4: Error in predicting well properties at all well locations for each cross-validation attempt. The averages do not include error in the prediction effort including all wells, indicated by the N/A under "without well \#."

Another method used to examine the effectiveness of texture attributes is to examine how accurately well-properties can be estimated when wells are removed from the optimum model selection. This technique, known has cross-validation, has been used for log property prediction from seismic data, even when a small number of wells are available (Hampson et al, 2000; Hart and Balch, 2000). Each well is removed from the set of 7 vertical wells and an optimum model waveform is determined for each reservoir property. Each time a well was removed, a new optimum model waveform and associated equation is selected. The plots used to select these model waveforms are included in figure 10. A summary of the results of the cross-validation are included in tables $3 \& 4$. 

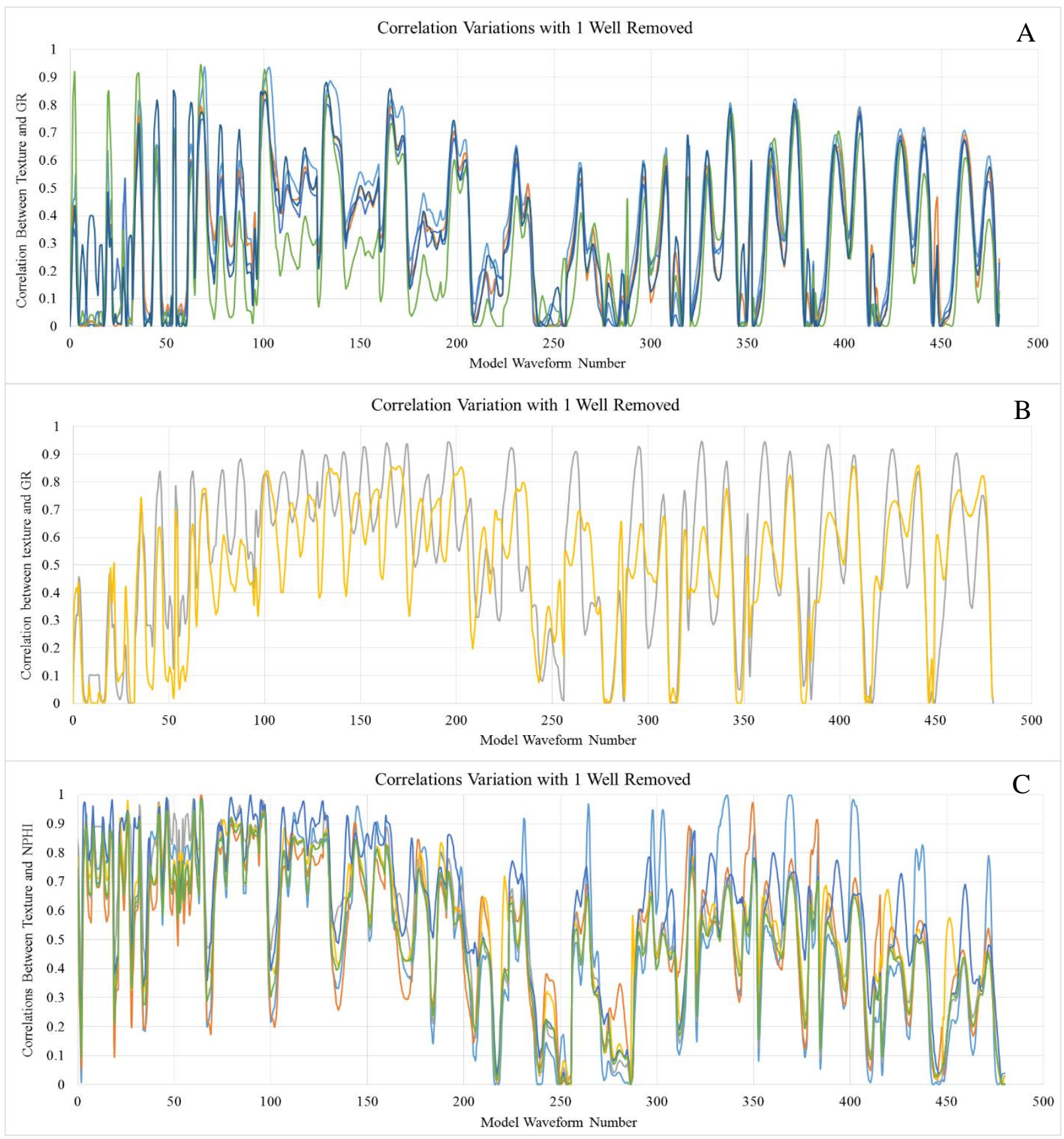

Figure 10: Cross-plots used in optimum model selection during cross-validation. Each line shows the relationship between correlation and model waveform number when a different well is removed from the process. It is apparent that the lines follow similar trends for porosity (figure $C$ ) and for gamma-ray (figures $A \& B$ ) regardless of which well is removed. The gamma-ray cross plots are split into two figures $(A \& B)$ to make it more clear to see. 
Once determination of an optimum model waveform is completed, and validity of its determination is checked to some degree, it is possible to compute reservoir property maps. Using the equation generated by the linear regression corresponding to the optimum model waveform, seismic texture can be converted into a 2-D reservoir property map. How the porosity and gamma ray varies laterally using this conversion can be seen in figures $11 \& 14$. The gamma-ray and porosity maps show spatial distribution of the estimated properties. The spatial resolution is approximately $100 \mathrm{ft} \times 200 \mathrm{ft}$ due to the lateral resolution of the original trace data. The information about the structural highs and lows are removed from these maps because the horizon based texture calculation is based off of a surface that follows the structure of the reservoir. Some effects of fractures can be seen in these maps.

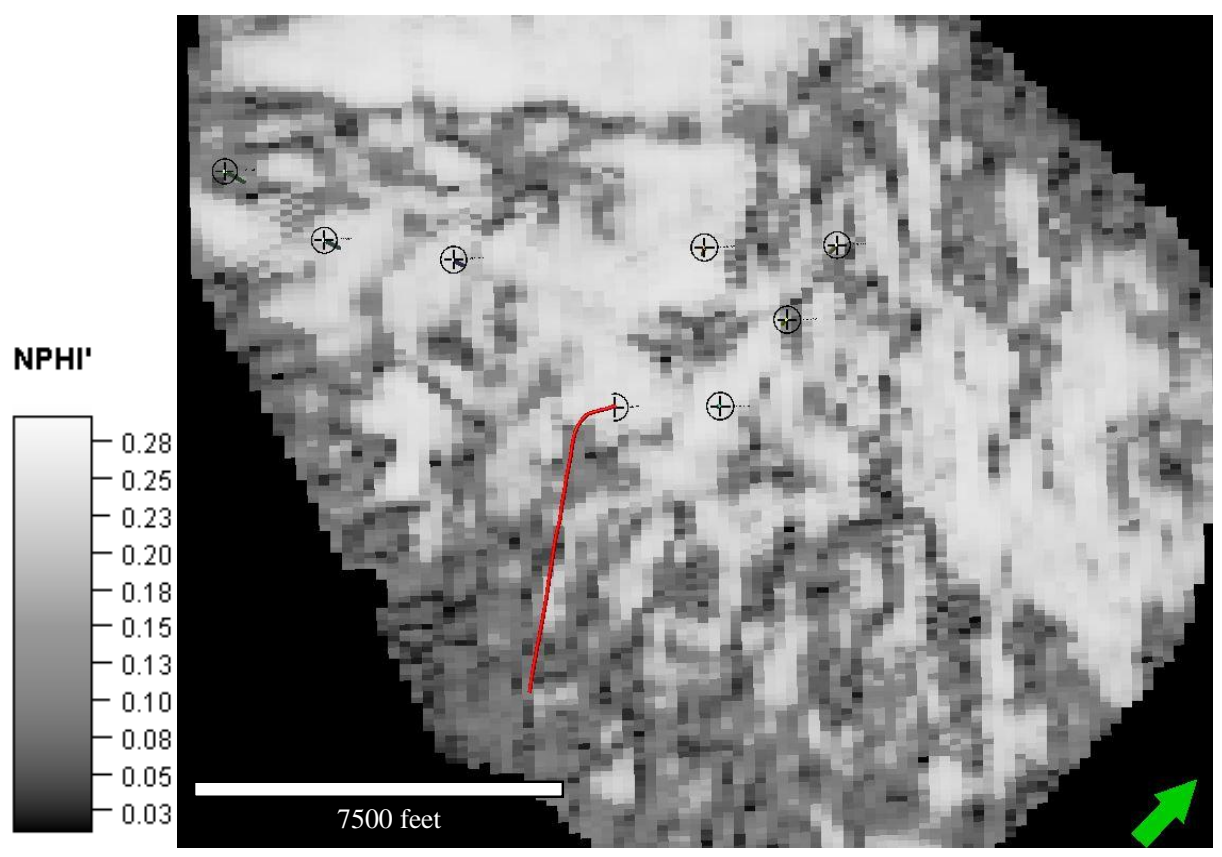

Figure 11: Map of porosity predicted from texture. Location of vertical wells and one horizontal well used to test prediction accuracy are shown. 


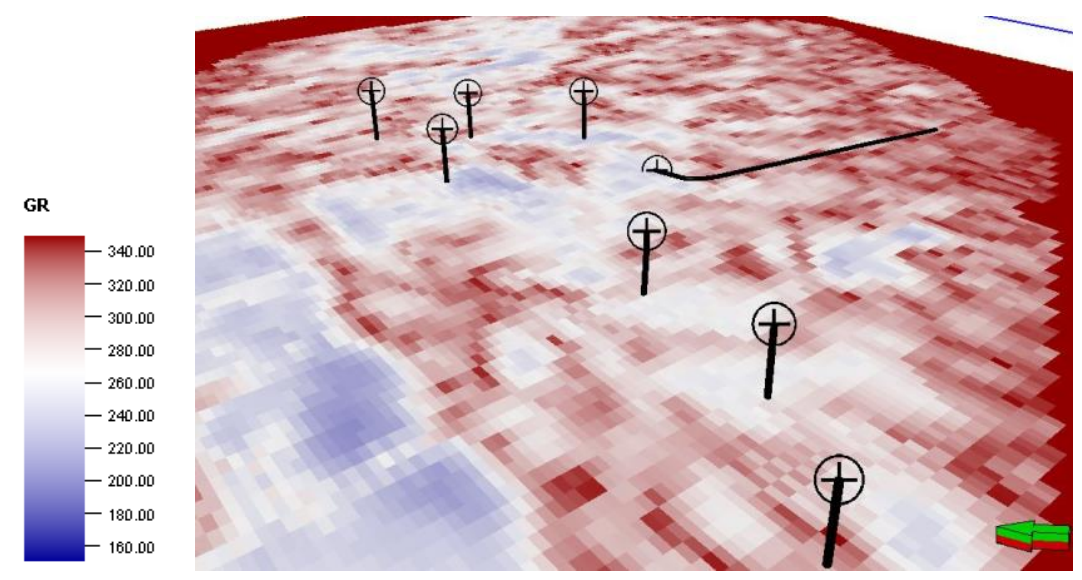

Figure 12: Map of predicted gamma-ray showing the seven vertical and one horizontal well used in the verification of the predicted properties. Lateral well was repositioned at the location of the property map in the spectral volume. Note that the lateral well has been transferred to a spectral volume and z-dimension remains constant at a desired position.

The information from the property maps is checked against the vertical well properties and results are provided in figure 13. One of the horizontal wells is also used to assess the property prediction map. To do this, the lateral portion of the well must be transferred into attribute space as illustrated in figure 12. The gamma-ray values from the map were extracted along the well path and compared to the logged gamma-ray from that well, included in figure 15 .

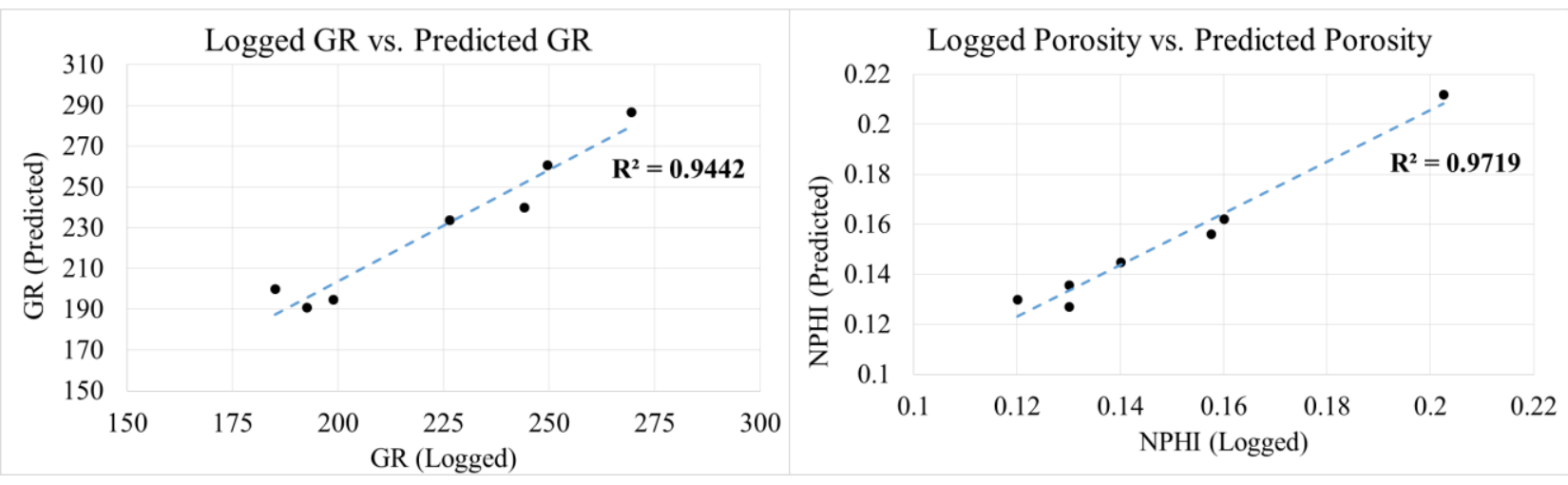

Figure 13: Cross-plots comparing the reservoir property data from well logs vs. the reservoir properties predicted from property map that was converted from texture data. Vertical well data was averaged at a 10 foot, 20 foot, and entire reservoir intervals. This shows the data from the entire reservoir interval size average. 


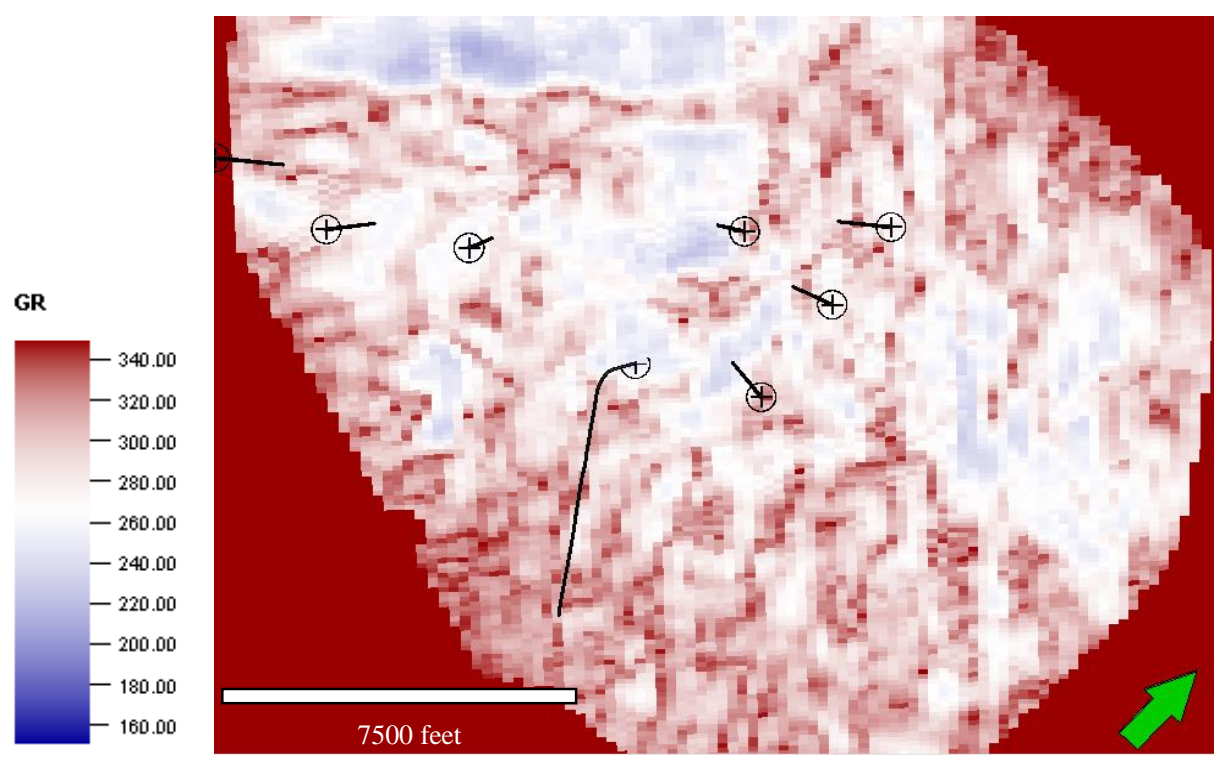

Figure 14: Map of gamma-ray predicted from texture data. Wells used to assess accuracy of gamma-ray prediction shown.

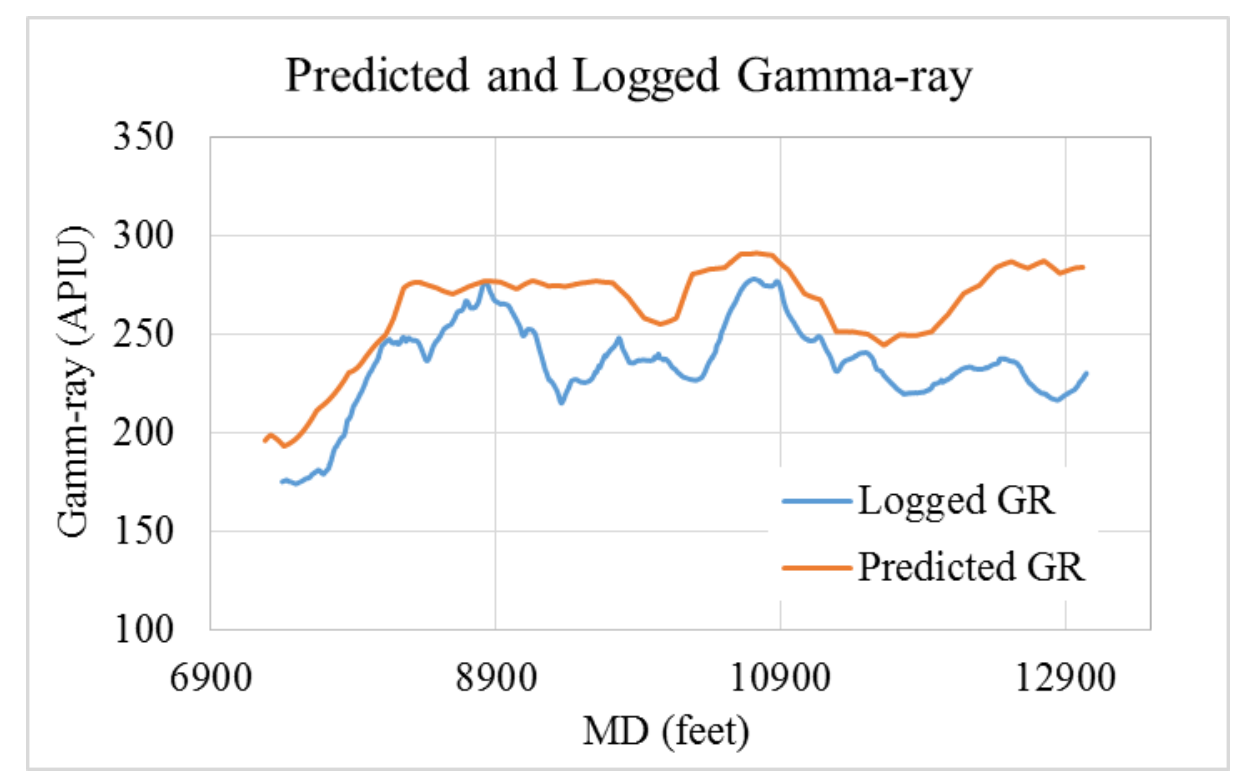

Figure 15: Comparison of the predicted and measured gamma-ray along the lateral portion of the wellbore. Predicted data comes from lateral well in figure 14. 


\subsection{Interpretation of Calibrations}

The first step of calibrating texture attributes to reservoir properties from well-data is to determine the optimum model waveform for each reservoir property. This is achieved by analyzing which model waveforms coincide with texture attributes that have the strongest correlation with reservoir properties at well locations. A possible downfall to this method is the use of a large number of model waveforms. It brings into question how statistically likely this method is to produce good correlations just due to the large number of models tried, rather than any meaningful correlation between texture attributes and reservoir properties. However, there is evidence against the significant correlations being random.

As illustrated in figure 8 , there is a definite trend associated with both the frequency and the window size of the model and its correlation to reservoir properties. In general, window sizes of 9,11 , and 13 samples (18ms, 22ms, and, $26 \mathrm{~ms}$ respectively) have the best correlations with reservoir properties. This is promising because the thickness of the Marcellus is represented by about $24 \mathrm{~ms}$ in thickness. The texture attributes that best correlate with reservoir properties are ones that consider an amount of data approximately represented by the Marcellus, and ones that incorporate seismic data from outside the reservoir tend to correlate worse with reservoir properties.

The other component of the model waveform that varies is the frequency. This too has a trend with correlation to reservoir properties. Regardless of the window size, all of the waveform models used to produce an r-squared greater than 0.80 with gamma-ray had a frequency between $50 \mathrm{~Hz}$ and $70 \mathrm{~Hz}$, about $5 \%$ of the range of included frequencies. Unlike the window size, a physical explanation for this is not clear, but it does suggest that high correlation strengths between texture and reservoir properties such as gamma-ray are not random due to a 
large number of models tried. Instead, there appears to be a systematic variation between how well texture correlates with reservoir properties, and the properties of the model waveform used to compute the attributes.

As a final measure to test whether or not strong correlations between texture and reservoir properties were random and due to large numbers of models being applied, petrophysical properties from outside the reservoir were applied to the same procedure to determine an optimum model. In this trial, very few high correlations were found. The results of this trial are included in figures $16 \& 17$.

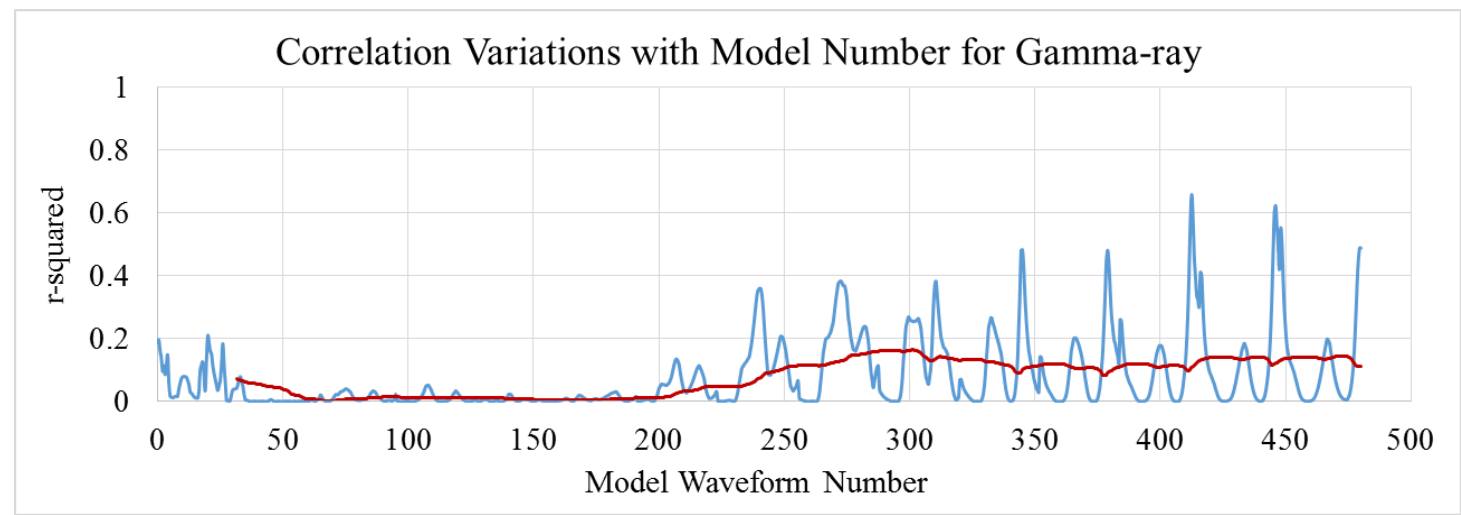

Figure 16: Optimal model selection cross-plot for gamma-ray data outside of the Marcellus shale. This is performed to test whether high correlations between texture data and gamma-ray data can be achieved due to the large number of model waveforms applied. The highest correlations from this plot are significantly lower than those found when using gamma-ray data from within the Marcellus. This provides some evidence that correlations are not random. 


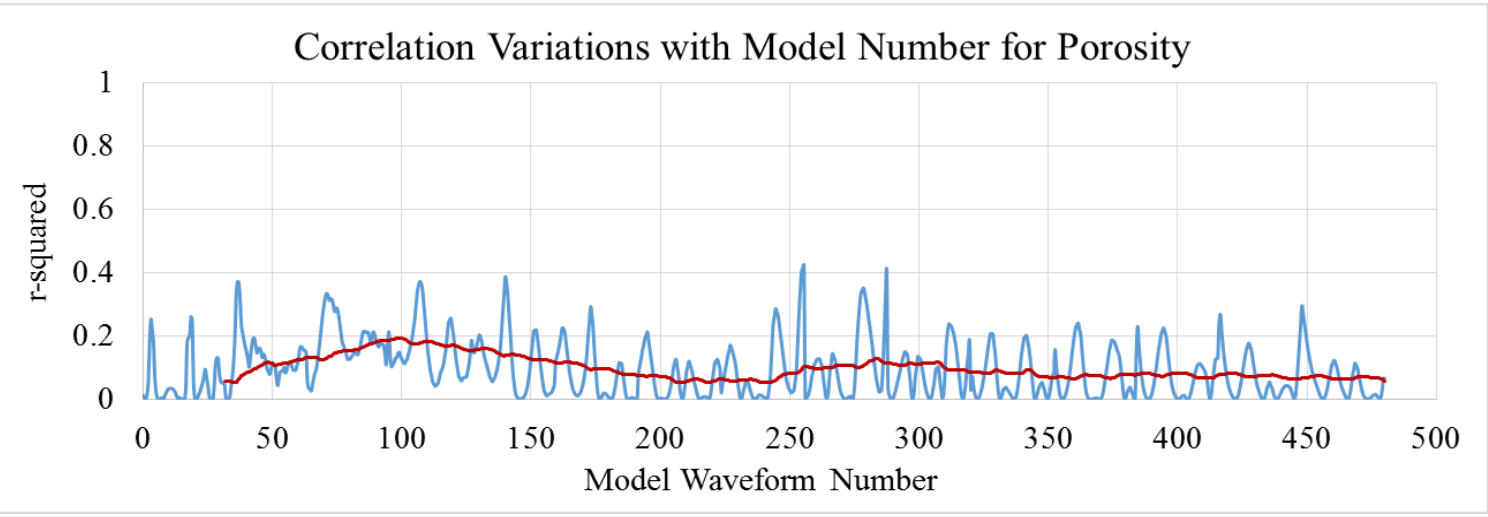

Figure 17: Optimal model selection cross-plot for porosity data outside of the Marcellus shale. This is performed to test whether high correlations between texture data and porosity data can be achieved due to the large number of model waveforms applied. The highest correlations from this plot are significantly lower than those found when using porosity data from within the Marcellus. This provides some evidence that correlations are not random.

The forward selection model results indicate that texture attributes are the most significant predictor in multi-attribute models, and are consistently associated with the least amount of error for each of the up-scaled reservoir properties. Adjusted r-squared multi-attribute analysis is used to observe a large number of combinations of attributes' ability to correlate with reservoir properties. Of the nearly 500 attribute combinations tested for each reservoir property, combinations using fewer than 5 variables were analyzed. Of those combinations, none had a stronger correlation with reservoir properties than texture alone. Meaning, without incorporating texture into a multi-attribute model, no combination of up to 5 other variables included in this study could correlate as well with reservoir properties as texture computed with the optimal model waveform.

The final product of calibrating texture attributes with well-data is to attempt to estimate the reservoir properties away from well locations. In this case, it is performed using texture data alone, with no other attributes. Only gamma-ray and porosity can be attempted to be predicted. These reservoir properties were chosen for calibration based on availability at almost all well 
locations. For vertical wells, there are very strong correlations ( $\mathrm{r}^{2}$ values of 0.94 and 0.97$)$ between logged reservoir properties and properties from the maps. This is somewhat expected, as those vertical wells were used in deriving the equation that transformed the texture data to gamma-ray and porosity. This good correlation indicates that when the equation is actually applied to the entire survey area, it works properly.

Trying to predict the gamma-ray along a horizontal well is a more significant test to the reservoir property map. Porosity cannot be validated with the horizontal well because it was not logged in the lateral portion. Information from the lateral well is not included at all in the derivation of the transforming equation, and it asses hundreds of predicted cells of the map rather than just a few as the vertical wells do. Figure 15 shows the comparison between the predicted and logged data for the lateral well. The logged data is presented as a moving average with a 200 foot window, to match the size of the cells of the property map. The predicted gamma-ray trend along the well path follows a similar trend as the logged property, particularly considering the lateral resolution of the seismic data compared to that of the well data.

Cross-validation is used to observe the error in predicting reservoir properties when wells are removed from the process of generated the transformation equations. Tables $3 \& 4$ show that there is commonly a low amount of error in prediction when wells are removed, regardless of which well it was. This is promising because it indicates that there are no leverage points in the equation building process. No well(s) data falls outside the prediction by other well(s) data to change the resulting prediction equation significantly. In addition, the relationship between optimum models and the correlation strength to well-data is very similar regardless of what well is removed from the process, as illustrated in figure 10. It supports both the optimal model waveform selection and the resulting prediction equation that regardless of which well is 
removed from the calibration, the resulting optimal model waveforms are almost always the same and the prediction equations changes very slightly.

\subsection{VOLUME PROCESSING USING TEXTURE ATTRIBUTES}

\subsection{Methodology}

The basics of computing waveform model regression is outlined in section 4.1. Unlike spectral volumes, applying texture attributes for structural interpretations results in volumes that maintain the dimensionality of the amplitude (input) data. This is done by positioning the attribute values at the same $\mathrm{x}, \mathrm{y}$ position as the input and the z-position at the center of the analysis window that each respective attribute value is computed. One model waveform is used to perform waveform model regression for an entire input volume. The model waveform starts at one input trace and is shifted along its entirety. At each step, linear regression is performed and the slope is output to the resulting volume at the center of the analysis window location. Once every input trace has been used, the resulting volume can be used for interpretation.

To assess the ability of texture attributes to increase interpretive capabilities, visual inspection of the attribute volumes was performed and fractures/ faults were interpreted from the volumes manually. In addition, variance and curvature calculations were performed using the texture volumes as input rather than amplitude. This will investigate whether texture is viable when used in conjunction these more common attributes and compare attribute volumes using an unbiased process. 


\subsection{Volume Processing Results}

Like many geometrical attributes, the prominent advantage of texture attributes for volume processing comes by visualizing attribute volumes. Attribute volumes were created using single cosine model waveforms of four window sizes. These models are defined by 7,11 , 15 , and 29 sample window sizes, and frequencies of $71 \mathrm{~Hz}, 45 \mathrm{~Hz}, 33 \mathrm{~Hz}$, and $17 \mathrm{~Hz}$ respectively. The purpose of doing this is to analyze the effect that different models have on resolving features, and visual results are provided in figure 18.

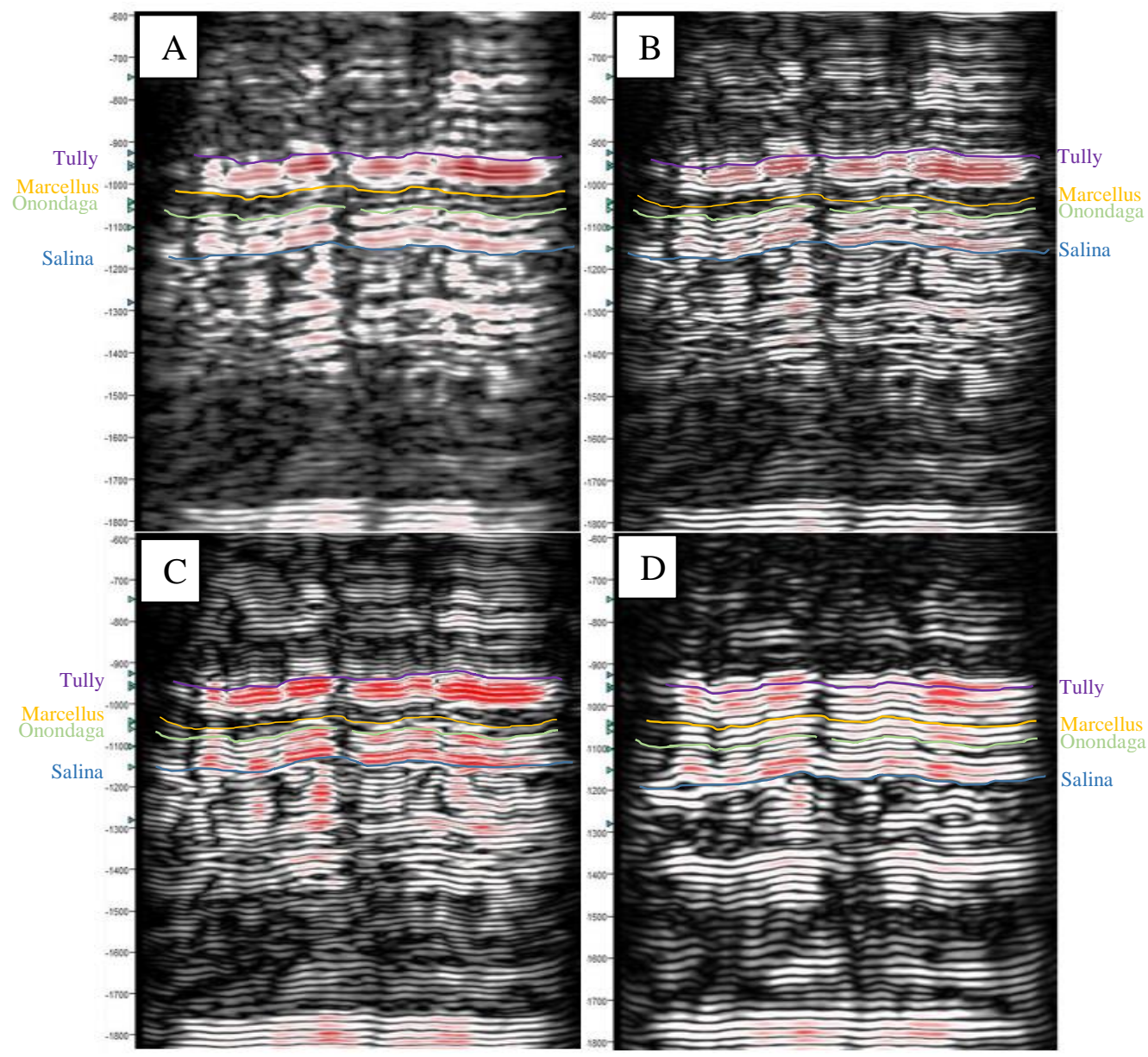

Figure 18: Four of the same inlines oriented NE/SW showing texture data calculated using 7(A), 11(B), 15(C), and 29(D) sample window sizes. Each inline presents varying ability to identify fractures, and differentiate detachment zone from overlying strata. Large fault shown is one of the cross-strike, strike slip faults. 
Faults were manually picked from two of the texture attributes volumes to observe any effects of using different model window sizes on the ability to interpret faults. First, the attribute volume computed with a 29 sample window was used, followed by one using an 11 sample window. All of the faults interpreted from the 29 sample window size volume can be interpreted in the 11 sample window size volume, but more faults can be interpreted by using the smaller window size volume. Though smaller window sizes generally leads to an appearance of more fractures, the smallest window size used to compute texture (7 samples) resulted in some reduction of interpretive capabilities.

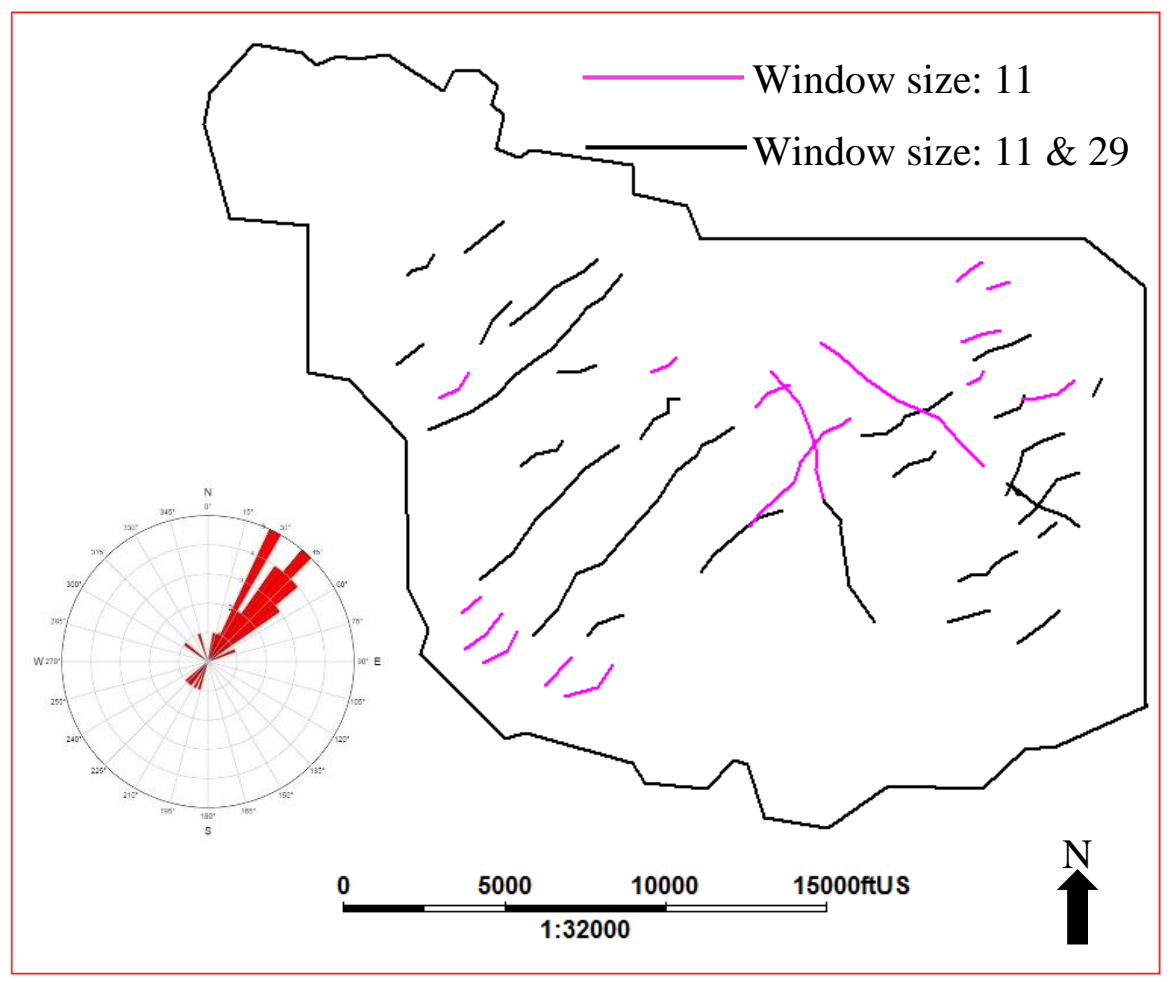

Figure 19: Map of fractures interpreted from volumes computing using an 11 and 29 sample window size. Black lines indicate traces of fractures that could be detected in both attribute volumes while pink lines indicate fractures that could only be detected using the volume computed with a smaller window size. 
To better understand why this is the case, attributes were computed along a single trace for each window size to view the effect of window size on feature detection. Figure 20 shows the results of computing texture using three window sizes.

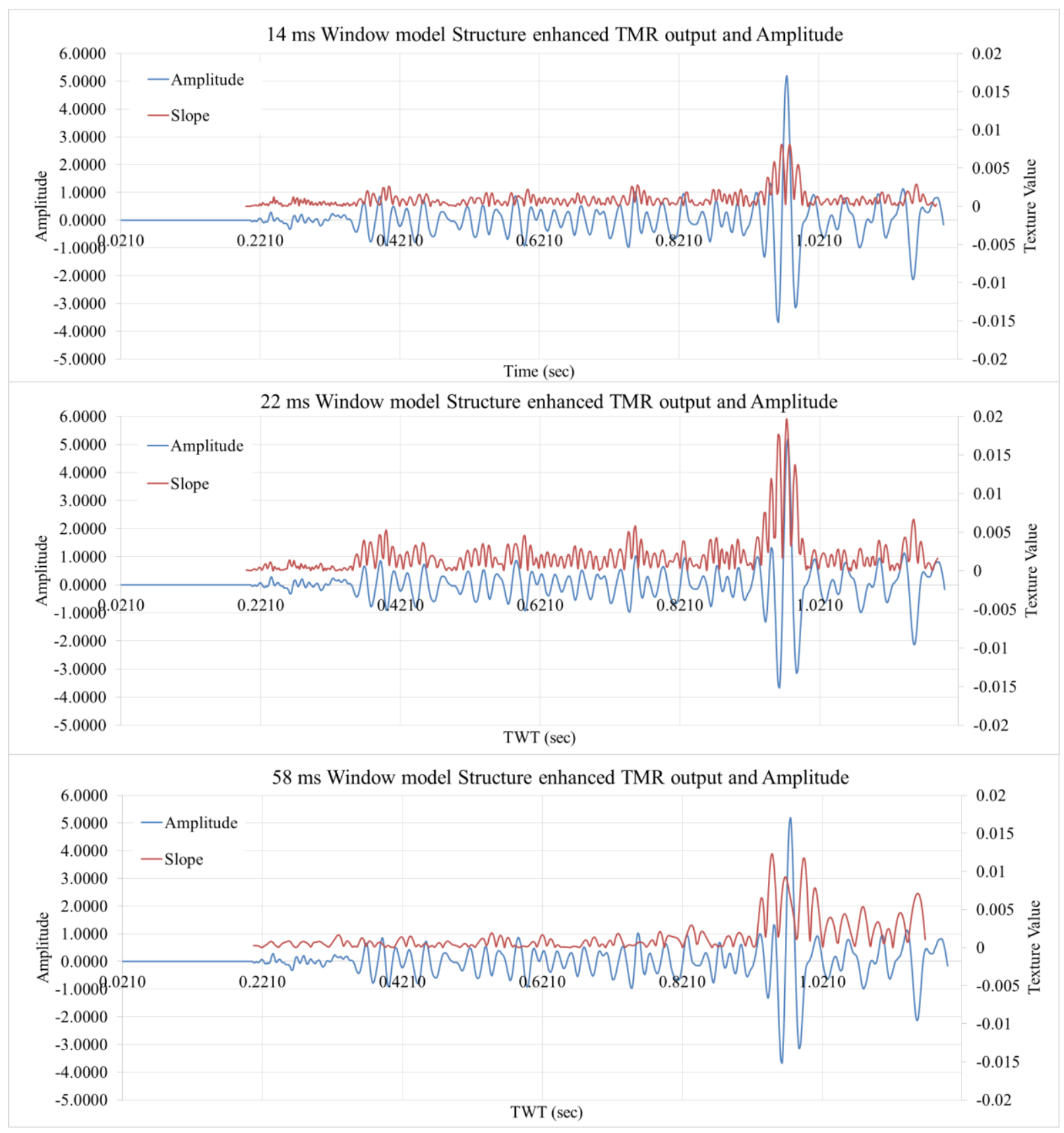

Figure 20: Waveform model regression output as used in volume processing applications for three model waveform window sizes. The same amplitude trace is used for each window size, while the output texture data varies. 
Variance and curvature were applied to the texture attribute volumes in order to see if texture attributes can be used in conjunction with conventional geometric attributes for enhanced structural interpretations. Results of this application show that lineaments detected by variance attributes vary when different model waveforms are used to compute them. Figure 21 shows results for variance applied to amplitude and three texture attribute volumes at time $=1078 \mathrm{~ms}$.
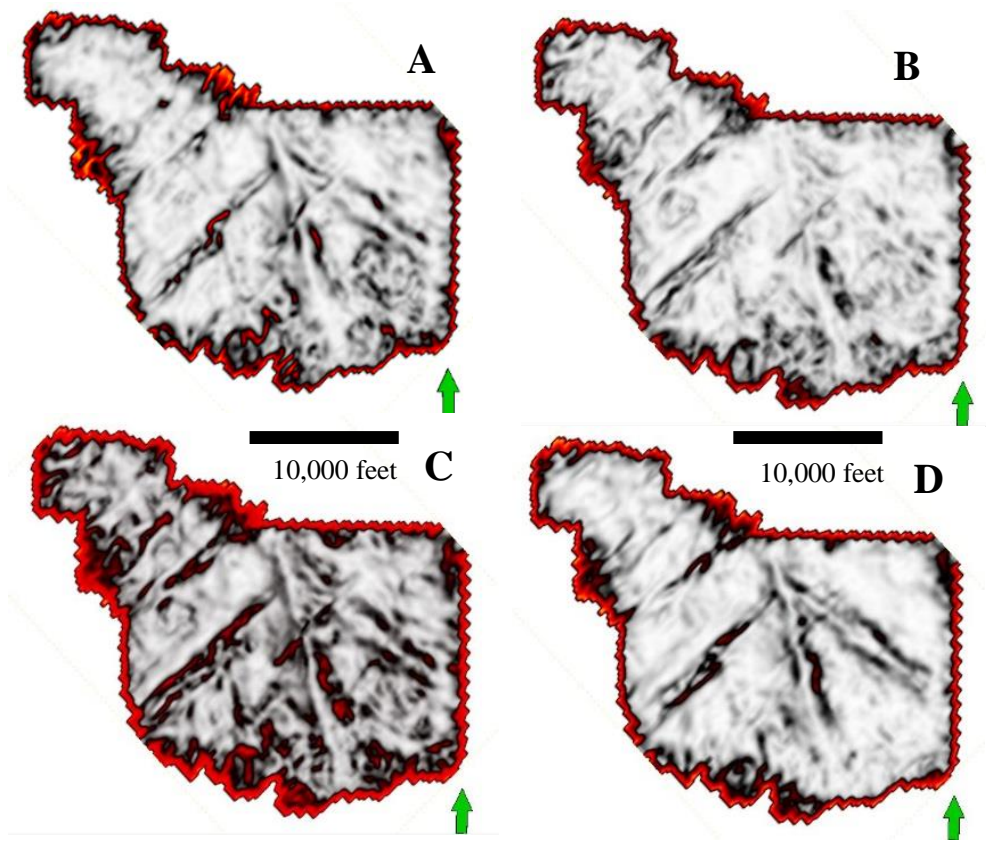

Figure 21: Variance attribute applied to amplitude volume (A), and texture volumes using a 7 sample window $(B), 11$ sample window $(C)$, and a 29 sample window $(D)$.

There are also differences in interpreting faults from curvature attributes when applied to amplitude data and texture data. Regardless of the window size used to compute the texture volumes, applying curvature attributes results in generally the same ability to resolve faults/fractures, but it differs from results of applying curvature to amplitude data. Because using texture in volume processing applications is designed to highlight faults, they appear more distinct when curvature attributes are applied, as illustrated by figure 22. 

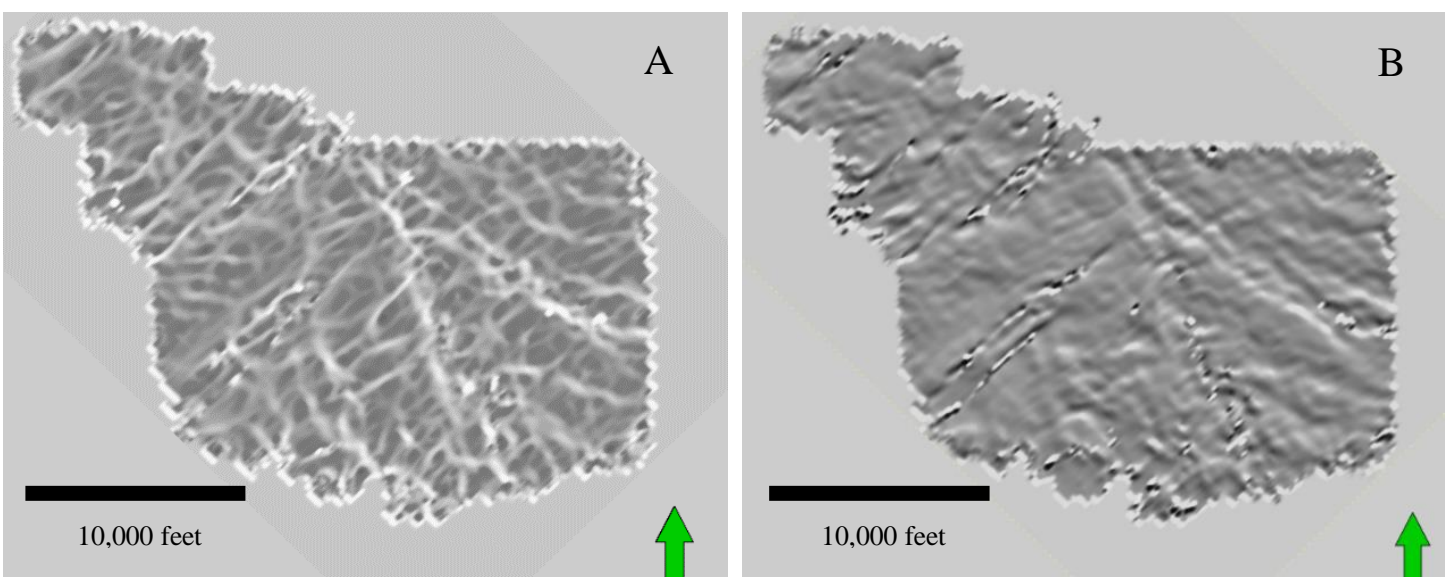

Figure 22: Curvature attribute applied to amplitude data (A) and texture data computed using a 11 sample window $(B)$. Both time slices are located at $1078 \mathrm{~ms}$, interpreted to be near the base of the reservoir interval.

A comparison of amplitude data and texture data in cross section highlights the most important potential benefit of using texture data, being interpretability. Enhanced visibility of seismic features brought about by using an appropriate window size and frequency model is the most crucial and basic reason to consider texture as a viable attribute for structural interpretations. Figure 22 illustrates the difference in feature visibility when applying texture attributes.
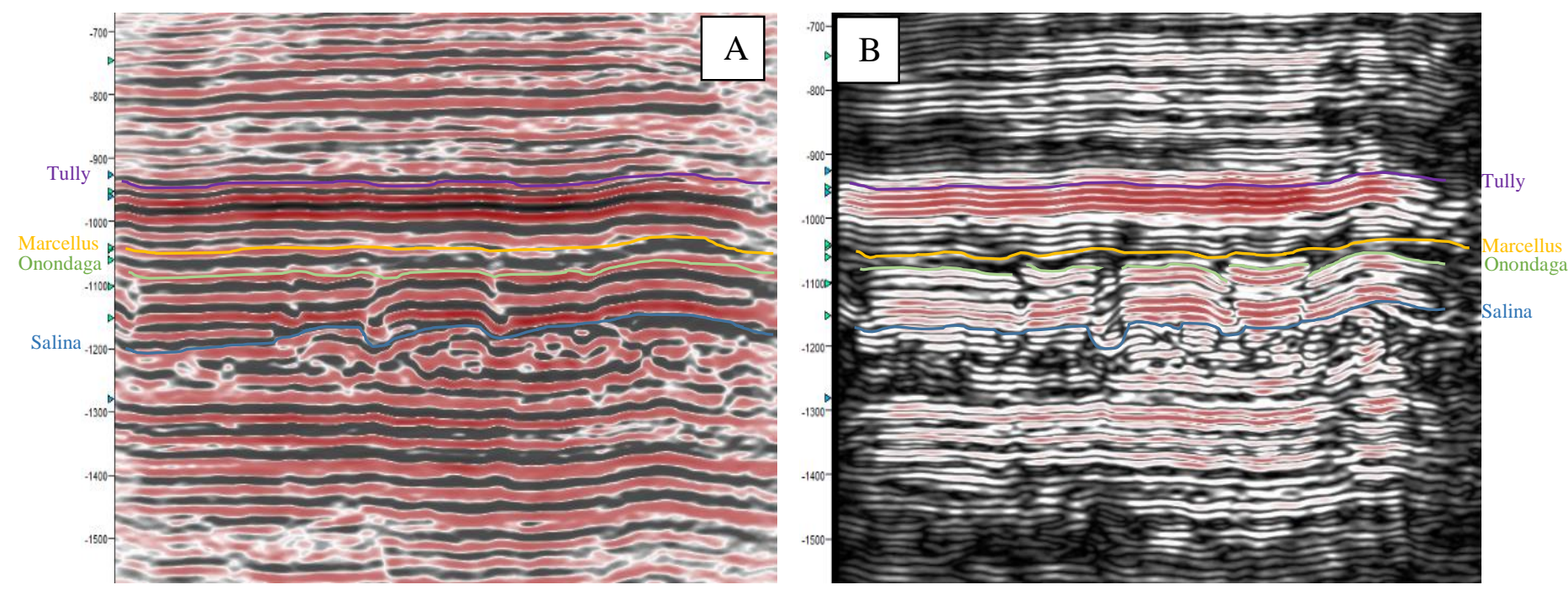

Figure 23: Inline of amplitude data $(A)$ and texture data computed using an 11 sample window $(B)$. 


\subsection{Structural Analysis Results}

From the seismic data, it is interpreted that three types of faults/fractures are present.

One type is reverse faults that terminate in the Salina detachment and propagate somewhere into the Hamilton group, but are not associated with significant offset of reflectors or changes in salt thickness. The features primarily strike between $35^{\circ}$ and $50^{\circ}$ and almost exclusively dip to the southeast. These features can only be identified by interpreting attribute volumes and are laterally less continuous than the other two fracture/fault types.

Another feature type identified in the seismic data are faults commonly occurring in pairs that are associated with offset through the reservoir and thickness changes in the underlying salt. These features are apparent in time-structure maps and in cross section. These features generally terminate in the upper extent at the top of the Marcellus and in the lower extent in the Salina detachment.

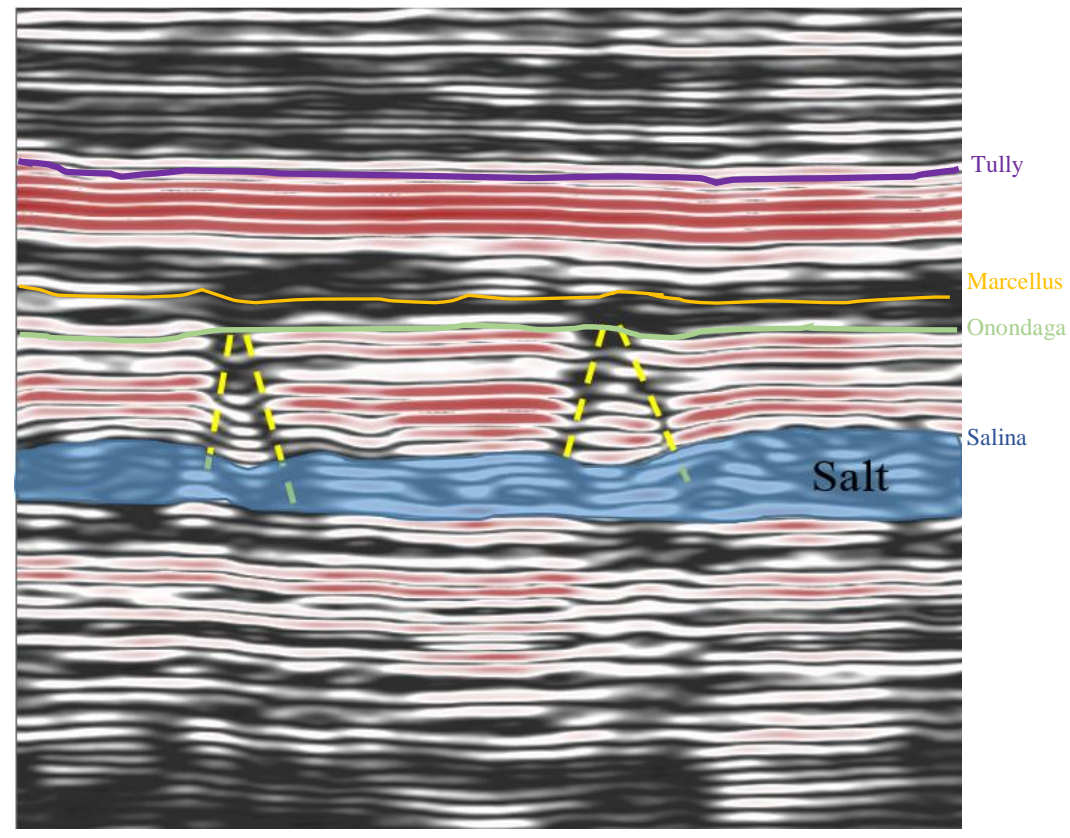

Figure 24: Cross section showing examples of paired faults associated with thinning of the underlying salt. Texture data is used to interpret these faults and texture data computed with an $22 \mathrm{~ms}$ window is displayed above. 
The third feature type identified in the seismic data is interpreted as two near vertical NW/SE trending strike slip faults, contrary to the orientation of other fractures in the survey area. These faults have the greatest vertical extent, spanning from well below the detachment to above the Tully. They are associated with some vertical offset, though smaller than the aforementioned paired faults. Both of the faults have a length of at least 3 miles and appear to intersect in the northwest portion of the survey (figures $6 \& 18$ ).

\subsection{Volume Processing Interpretations}

From a visual perspective, texture attributes can enhance interpretive capabilities. The vertical resolution of the seismic signal appears to be higher, because texture attributes accentuate changes in amplitude according to the size of the analysis window being employed. After examining texture attribute volumes computed with different window sizes and the single trace outputs in figure 20, it is apparent that window size is crucial when employing waveform model regression. When an analysis window is too large, some changes in the input amplitude go undetected in the computed texture. When an analysis window is too small, the regression computed between the data trace and model is often near zero, or cannot encompass significant patterns in the amplitude trace. When the window size is appropriate, subtle changes in amplitude are detected and the differences in adjacent traces can be accentuated, which is the main purpose of the WMR and soft-calibration is used to compute texture attributes. In the case of this seismic survey, model waveforms with window sizes of 11 and 15 samples appear to be best at producing volumes for visual interpretations.

To detect faults, one looks for offset of seismic reflectors or apparent breaks in other wise continuous reflection horizons. Because texture attribute computed with various window sizes 
detect these apparent faults differently, more than one texture volume may be necessary to properly interpret all discontinuities within one survey area. By looking at the faults picked from the 11 sample and 29 sample volumes (figure 19), its apparent that some portions of continuous faults, and some entire faults create changes in amplitude that are different than others. It is unclear as to whether the faults are actually different sizes, but it's important to note that not all texture attributes should be treated equally when trying to identify seismic features of different relative size.

Applying geometric attributes to texture data is possible and the results are believed to be significant. Applying variance to amplitude data and various texture volumes produces results that would lead to slightly different fault interpretations. As observed in figure 21, interpretations of faults in through the reservoir using variance data would differ, and most likely be best using texture data computed with an 11 sample window as input. One instance in which the window size does not matter significantly appears to be when texture is used as an input for curvature computation. Various texture volumes were used as input, but the resulting curvature data is almost identical. However, curvature results are different when the input is amplitude. Figure 22 illustrates that NE trending faults are more precisely outlined using curvature when texture is used as the input.

\subsection{Structural Analysis Interpretations}

The structure of the Marcellus Shale at the location of this seismic survey has multiple feature types that could affect horizontal drilling due to the offset associated with them. Most faults interpreted in the seismic data are parallel to the majority of the fold axes in central Pennsylvania. Though there are a large number of NE oriented faults, only certain types appear 
to be associated with offset through the reservoir. This type of feature has been identified in other regions of the Marcellus as kink-bands and are associated with pop-down structures in the underlying salt. In the seismic data, these are differentiated from other northeast trending fractures in two ways. One way is that the faults appear in pairs, dipping in opposite directions (figure 24). In addition, these features are associated with distinct changes in salt thickness.

The other type of feature associated with offset in the reservoir are two large faults oriented at $340^{\circ}$ and $310^{\circ}$. These faults are cross-strike to the orientation of the structural front and most fault and fold axes in the area. These faults are expressed by offset at both the top and bottom of the salt, as opposed to the kink-bands which are only expressed at the top of the salt. This indicates that the detachment facilitates the structure-parallel faults, but not the structureperpendicular faults. The offset from the structure-perpendicular faults can be seen far above and below the reservoir. These are interpreted as large high-angle strike slip faults.

In an attempt to determine transport direction above the detachment, texture attributes were employed to interpret faults in the detachment that terminate in overlying strata. It is typically difficult to interpret fractures in the detachment, but by applying texture attributes with a relatively small (11 samples) window size, 40 fractures were interpreted with a northeast trend and a length of at least 1000 feet. Of the 40 fractures, 34 of them are dipping to the south east. This supports a transport direction to the northwest. Because the cross-strike faults are not facilitated by the detachment, it's difficult to use them to determine transport direction. Therefore the transport direction is cautiously interpreted as northwest. 


\section{CONCLUSIONS}

The main provisions of this study include an analysis of waveform model regression based texture attributes and their viability to calibrate with well data and increase seismic visualization. Like any data-driven prediction methods, there are uncertainties about the correlations that are derived, but evidence supports a connection between texture attributes and reservoir properties. Model waveform window size is generally best calibrated to reservoir properties when it is approximately the size of the reservoir. There is a connection between model frequency and correlation with reservoir properties. Though large amounts of model waveforms were tested, the high strength of correlation between texture and reservoir properties appears to be non-random, and a function of using the correct window in the seismic data that corresponds to the reservoir.

It is observed that using texture attributes enhances the visibility of faults and structure of the 3D seismic data. The ability to resolve features is dependent on the window size and frequency of the model waveform being employed. Smaller window sizes generally lead to an apparent increase is visibility, but there is a point when the window size becomes too small to detect important changes in the input data. Texture attributes prove useful as input data for other conventional attributes such as variance and curvature. It is interpreted that salt facilitated offset exists in the Marcellus Shale in the form of kink-bands. Large high-angle strike-slip faults are cross-strike to the regional structure and are vertically extensive in this area.

Waveform model regression based texture is not an all-encompassing attribute and should be used according to an intended purpose. Though this case study shows that it correlates well with changes in reservoir properties, care should be taken when developing relationships 
with no obvious rock physics basis. With this being said, texture attributes have potential for application in estimating reservoir properties and enhancing visual interpretations. 


\section{REFERENCES}

AlBinHassan, N., Wang, Y., 2011, Porosity prediction using the group method of data handling, Geophysics, vol. 75, no. 5, pp. O15 - O22.

Bagheri, M., Riahi, M. A., 2015, Seismic facies analysis from well logs based on supervised classification scheme with different machine learning techniques, Arabian Journal of Geosciences, vol. 8, pp. $7153-7161$.

Barnes, A., 2016, Handbook of Poststack Seismic Attributes, Society of Exploration Geophysicists, Geophysical Reference Series no. 21.

Bosch, M., Mukerji, T., Gonzalez, E.F., 2010, Seismi inversion for reservoir properties combining statistical rock physics and geostatistics: A review, Geophysics, vol. 75, issue 5, pp. 75A $165-75 \mathrm{~A} 176$.

Bowers, C., 2014, Analyzing Fracture Stimulation of Middle Devonian Strata in Clearfield County Pennsylvania Using a 3D Geomechanical Fault Model and Microseismic, Masters Thesis, West Virginia University.

Chopra, S., and Alexeev, V., 2005, Application of texture attribute analysis to 3D seismic data, Canadian Society of Exploration Geophysicists, vol. 30, no. 7.

Chopra, S., Marfurt, K., 2005, Seismic Attributes - A Historical Perspective, Geophysics, vol. 70, no. 5, p 3SO- 28SO, Society of Exploration Geophysicists, 75th Annual Meeting.

Cotter, E., and Inners, J.D., 1986, Silurian stratigraphy and sedimentology in the Huntingdon County area, in Sevon, W.D., ed., Selected geology of Bedford and Huntingdon counties Guidebook for the Annual Field Conference of Pennsylvania Geologists 51, Field Conference of Pennsylvania Geologists, p. 27-39.

Department of Conservation and Natural Resources Digital Data, http://denr.state.pa.us/ topogeo/publications/digitaldata/index.htm

Donahoe, T., and Gao, D., 2016, Application of 3D seismic attribute analysis to structure interpretation and hydrocarbon exploration of southwest Pennsylvania, Central Appalachian Basin: A Case Study, Interpretation, v. 4, p. T291 - T302.

Engelder, T., Lash, G.G., Uzcategui, R.S., 2009, Joint sets that enhance production from the Middle and Upper Devonian gas shales of the Appalachian Basin, AAPG Bulletin, v. 93, no. 7, p. 857-889).

Ettensohn, F.R., 1985, The Catskill delta complex and the Acadian orogeny: A model, Geological Society of America Special Paper 201, p. 39-49. 
Gao, D., 2004, Texture model regression for effective feature discrimination: Application to seismic facies visualization and interpretation: Geophysics, v. 69, pp. 958-967.

Gao, D, 2006, Theory and Methodology for Seismic Texture Analysis: Implications for Seismic Facies Visualization and Interpretation, Gulf Coast Association of Geological Societies Transactions, v. 56, p. 217-226.

Gao, D., 2011, Latest develoments in seismic texture analysis for subsurface structure, facies, and reservoir characterization: A review, Geophysics, vol. 76, no.2, p.W1-W13.

Gao, D, and T. Duan, 2017, Seismic structure and texture analysis for fractured reservoir characterization: An integrated workflow.

Gillespie, P., Van Hagen, J., Wessels, S., Lynch, D., 2014, Hierarchical kink band development in the Appalachian Plateau decollement sheet, AAPG Bulletin, v. 99, no. 1, pp. 51-76.

Hampson, D. P., Schuelke, J., Quirein, J., 2000, Using multi-attribute transforms to predict log properties from seismic data, Exploration Geophysics, vo. 31, issue 3, pp. 481-487.

Harper, J.A., 1999, The Geology of Pennsylvania, Chapter 7: Devonian, Stratigraphy and Sedimentary Tectonics, Bureau of Topographic and Geologic Survey DCNR.

Hatcher, R. D., Jr., 1989, Tectonic synthesis of the U.S. Appalachiains, in Hatcher, R.D., Jr., Thomas, W.A., and Viele, G.W., eds, The Appalachian-Ouachita Orogen in the United States: Boulder, Colorado, Geological Society of America, The Geology of North America, v. F-2, p. 511-529.

Hart, B.S., and Balch, R.S., 2000, Approaches to defining reservoir physical properties from 3-D seismic attributes with limited well control: An example from the Jurrassic Smackover Formation, Alabama, Geophysics, Vol. 82, no. 2, pp. 368-376.

Inks, T.L., Engelder, T., Golob, B., Hocum, J.S., O’Brien, D.G., 2014, Comparison of Marcellus Fracturing Using Azimuthal Seismic Attributes Published Data from Outcrop Studies, URTeC: 1922505.

Koson, S., Chenrai, P., Choowong, M., 2014, Seismic Attributes and Their Applications in Seismic Geomorphology, Bulletin of Earth Sciences of Thailand, vol. 6, no. 1, pp. 1 - 9.

Laughery, C.D., 1999, The Geology of Pennsylvania, Chapter 6: Silurian and Transition to Devonian, Stratigraphy and Sedimentary Tectonics, Bureau of Topographic and Geologic Survey DCNR. 
Lash, G., Loewy, S., and T. Engelder, 2004. Preferential jointing of Upper Devonian black shale, Appalachian Plateau, USA: Evidence supporting hydrocarbon generation as a jointdriving mechanism: in Cosgrove, J.W., and Engelder, T., eds., The initiation, propagation and arrest of joints and other fractures, Geological Society of London Special Publications, v. 231, p. 129-151.

Li, F., Lu, W., 2014, Coherence attribute at different spectral scales, Interpretation, vol. 2., no. 1, pp. $1-8$.

Mount, V., 2014, Structural stile of the Appalachian Pleateau fold belt, north-central Pennsylvania, Journal of Structural Geology 69, pp. 284-303.

Oliver, W. A., Jr., de Witt, Wallace, Jr., Dennison, 1. M., and others (1967), Devonian of the Appalachian basin. United States, in International Symposium on the Devonian System, v. I, Calgary, Alberta Society of Petroleum Geologists, p. 1001-1040.

Pederson, L., Ryan, S., Sonneland, L., 1996, Seismic Snapshots for Reservoir Monitoring, Oilfield Review Winter 1996, pp. 32-43.

Read, J. F., 1989, Evolution of Cambro-Ordovician passive margin, U.S. Appalachians, in R. D. Hatcher, W. A. Thomas, and G. W. Viele, eds., The Appalachian-Ouachita orogen in the United States: Geological Society of America, Geology of North America, v. F-2, p. 4257.

Roberts, E., 2013, Structure Segmentation and Transfer Faults in the Marcellus Shale, Clearfield County, PA: Implications for Gas Recovery Efficieny and Risk Assessment in the entral Appalachian Basin Using \#D Seismic Attribute Analysis, Masters Thesis, West Virginia University.

Ryder, R.T., Sweazy, C.S., Trippi, M.H., Lentz, E.E., Avary, K.L., Harper, J.A., Krappel, W.M., Rea, R.G., 2007, In search of a Silurian Total Petroleum System in the Appalachian basin of New York, Ohio, Pennsylvania, and West Virginia, USGS Open File Report 20071003.

Ryder, R.T., Swezey, C.S., Crangle, R.D., Jr., and Trippi, M.H., 2008, Geologic cross section EE' through the Appalachian basin from the Findlay arch, Wood County, Ohio, to the Valley and Ridge province, Pendleton County, West Virginia: U.S. Geological Survey Scientific Investigations Map 2985, 2 sheets, 48-p. pamphlet.

Ryder, R.T., 1992, Stratigraphic framework of Cambrian and Ordovician rocks in the central Appalachian basin from Lake County, Ohio to Juniata County, Pennsylvania, USGS Miscellaneous Investigation Series.

Schultz, p.s., Ronen, S., Hattori, M., Corbett, C., 1994, Seismic-guided estimation of log properties: Part 1: A data-driven metholodology, The Leading Edge 13, pp. 305 - 315. 
Sinha, A.K., Bartholomew, M.J., 1984, Evolution of the Grenville terrain in the central Virginia Appalachians, The Grenville Event in the Appalachians and Related Topics p. 175-187.

Taner, M. T., J. S. Schuelke, R. O’Doherty, and E. Baysal, 1994, Seismic attributes revisited: 64th Annual International Meeting, SEG, Expanded Abstracts, 1104-1106. Ver Straeten, C.A., 2010, Lessons from the foreland basin: Northern Appalachian basin perspectives on the Acadian orogeny, Geological Society of America Memoir 206, p. 251-282, doi: 10.1130/2010.1206(12).

Todorov, T., Stewart, R., Hampson, D., Russell, B., 1998, Well log prediction using attributes from 3C-3D seismic data, Society of Exploration Geophysicists Expanded Abstracts, SEG Annual Meeting.

Ver Straeten, C.A., 2010, Lessons from the foreland basin: Northern Appalachian basin perspectives on the Acadian orogeny, Geological Society of America Memoir 206, p. 251-282.

Wiltschko, D.V., Chapple, W.M., 1977, Flow of Weak Rocks in Appalachian Plateau Folds, AAPG Bulletin, vol. 61, issue 5, pp. 653-670.

Younes, A.I., and Engelder, T., 1999, Fringe Cracks: Key strucutres for the interpretations of the progressive Alleghenian deformation of the Appalachian plateau, GSA Bulletin, v. 111; no. 2, p. 219-239.

Yuan, S., DeAngleo, M.V., Hardage, B.A., 2014, Interpretation of fractures and joint inversion using multicomponent seismic data- Marcellus shale example, Interpretation, vol. 2, no. 2, pp. SE55-SE62.

Zagorski, W. A., G. R. Wrightstone, and D. C. Bowman, 2012, The Appalachian Basin Marcellus gas play: Its history of development, geologic controls on production, and future potential as a world-class reservoir, in J. A. Breyer, ed., Shale reservoirs-Giant resources for the 21st century: AAPG Memoir 97, p. 172-200. 